\title{
A dinâmica do emprego na indústria brasileira: com- portamento recente (2006-2010) e o efeito de restrições de mão de obra especializada
}

\author{
Edson Paulo Domingues \\ Professor - Universidade Federal de Minas Gerais (UFMG/ CEDEPLAR) \\ Endereço: Av. Antônio Carlos, 6627 - Pampulha - Belo Horizonte/MG \\ CEP 31270-901 - E-mail: epdomin@cedeplar.ufmg.br
}

\section{Kênia Barreiro de Souza \\ Pesquisadora - Universidade Federal de Minas Gerais (UFMG) \\ Endereço: Av. Antônio Carlos, 6627 - Pampulha - Belo Horizonte/MG \\ CEP 31270-901 - E-mail:keniadesouza@gmail.com \\ Débora Freire Cardoso \\ Pós-Doutoranda - Universidade Federal de Minas Gerais (UFMG/CEDEPLAR) \\ Endereço: Av. Antônio Carlos, 6627 - Pampulha - Belo Horizonte/MG \\ CEP 31270-901 - E-mail:dfreirecardoso@gmail.com}

\section{Terciane Sabadini Carvalho}

Professora - Universidade Federal do Paraná (UFPR/PPGDE)

Endereço: Avenida Prefeito Lothário Meissner, 632 - Térreo - Jardim Botânico - Curitiba/PR

CEP: 80210-070 - E-mail: terciane.carvalho@ufpr.br

\section{Flaviane Souza Santiago}

Pesquisadora - Universidade Federal de Minas Gerais (UFMG)

Endereço: Av. Antônio Carlos, 6627 - Pampulha - Belo Horizonte/MG

CEP 31270-901 - E-mail: santiago.flaviane@gmail.com

\begin{abstract}
Aline Souza Magalhães
Professora - Universidade Federal de Minas Gerais (UFMG/CEDEPLAR) Endereço: Av. Antônio Carlos, 6627 - Pampulha - Belo Horizonte/MG CEP 31270-901 - E-mail:alinesm@cedeplar.ufmg.br
\end{abstract}

\section{Admir Antônio Betarelli Júnior}

Professor - Universidade Federal de Juiz de Fora (UFJF)

Endereço: Rua José Lourenço Kelmer, s/n - Campus Universitário - São Pedro - Juiz de Fora/MG CEP: 36036-330 - E -mail: admir.betarelli@ufff.edu.br

Recebido: 04/04/2013. Aceito 12/03/2016.

\section{Resumo}

O comportamento da economia brasileira entre 2003-2008 pareceu indicar que o crescimento da indústria defrontava-se com a dificuldade de contratação de mão de obra especializada, como técnicos e engenheiros. Essa escassez pode representar um obstáculo ao desenvolvimento do país, especialmente ao dificultar a expansão de setores de maior conteúdo tecnológico. Este artigo analisa os efeitos da escassez de trabalho

- Este trabalho integra as pesquisas desenvolvidas no âmbito do projeto "Avaliação dos impactos de políticas industriais sobre o crescimento econômico" apoiado pela Capes (Edital PGPSE, n. 42/2014). 
especializado na economia brasileira, com especial atenção aos setores relacionados à indústria. Utiliza-se um modelo de equilíbrio geral computável especialmente capacitado para as questões tratadas no artigo. Os resultados das simulações indicam o impacto expressivo da dinâmica do investimento na demanda por engenheiros e técnicos; e que restrições no crescimento da oferta dessa mão de obra podem afetar principalmente a indústria de bens de capital e de insumos intermediários, relevantes para um amplo conjunto de setores da economia.

\title{
Palavras-Chave
}

Emprego. Indústria. Escassez de mão de obra. Equilíbrio geral computável.

\begin{abstract}
The recent behavior of the Brazilian economy between 2003-2008 seems to indicate that the industry growth runs up against the difficulty of hiring skilled labor, such as technicians and engineers. This shortage may pose an obstacle to the development of the country, especially to hinder the expansion of sectors with higher technological content. This paper analyzes the effects of the shortage of skilled labor in the Brazilian economy, with special attention to sectors related to the manufacturing. It uses a computable general equilibrium model specially qualified for the issues addressed in the paper. The results indicate the significant impact of investment dynamics in the demand for engineers and technicians, and those restrictions on the growth of labor supply that may affect mainly the industry of capital goods and intermediate inputs, relevant to a wide range of sectors economy.
\end{abstract}

\section{Keywords}

Employment. Manufacturing. Labor constraints. Computable general equilibrium.

\section{JEL Classification}

C68. D21.

\section{Introdução}

Os processos de globalização e abertura comercial, que se intensificaram no início da década de 1990, trouxeram mudanças estruturais nos modos de produção e na composição da demanda por trabalho no Brasil. De acordo com Slaughter e Swagel (1997), a mais importante tendência do mercado de trabalho mundial foi o aumento da demanda por trabalho mais especializado em detrimento da demanda por trabalho menos especializado. Na última década, o ciclo de crescimento mais acelerado pelo qual passou a economia brasileira impulsionou a produção e repercutiu no mercado de trabalho, trazendo à tona a discussão acerca da disponibilidade de mão de obra especializada para sustentar o crescimento. Em meio a esse debate, emergem termos como "escassez de mão de obra especializada" e 
especula-se a respeito de um possível "apagão" de pessoal técnicocientífico, ${ }^{1}$ em especial, de engenheiros (Nascimento et al., 2010; Pompermayer et al., 2011; Maciente e Araújo, 2011).

A possível escassez de mão de obra especializada não é um fenômeno que atinge apenas o Brasil, mas também países desenvolvidos que podem apresentar mismatch ${ }^{2}$ entre habilidades ofertadas e a demanda por trabalho. Estudos recentes têm apontado para certo descompasso, principalmente em períodos de recessão, entre o recrutamento de mão de obra especializada e a busca por emprego no mercado de trabalho norte-americano. Sahin et al. (2011) construíram um índice para o grau de mismatch na economia dos EUA a partir da dispersão entre a taxa de desemprego setorial e as vagas de emprego entre 2001 e 2011. Esses autores mostram que o índice cresceu acentuadamente no período da crise financeira, voltando a se estabilizar nos últimos anos. Faberman e Mazumder (2012), em estudo utilizando dados do U.S. Bureau of Labor Statistics ${ }^{3}$ observam um possível mismatch para o mesmo país. Os dados apontam que trabalhadores em ocupações nas quais moderada qualificação é requisitada não têm obtido ganhos em termos de emprego, a despeito da demanda crescente por esse tipo de mão de obra.

O mercado de trabalho brasileiro, por seu turno, revelou certo dinamismo na última década, acompanhando a trajetória crescente do nível de atividade e, assim, expandindo os empregos de maior qualificação, ao mesmo tempo em que reduzia o nível de informalidade. De acordo com Nascimento et al. (2010), a evolução da proporção de pessoas dispostas a obter emprego cresceu 3,2\% a.a. entre 2002 e 2005 e 1,2\% no triênio seguinte, e o aumento dos níveis de ocupação em 3,2\% a.a. entre 2002 e 2005 e em 2,0\% entre 2006 e 2008 são indicadores que corroboram a hipótese de que novos patamares se delineiam no nível geral de emprego. Além disso, durante esse período ocorreu uma incorporação mais intensa de trabalhadores entre 25 e 59 anos com mais de 11 anos de escolarização ao mercado. Dessa forma, face a tantas mudanças, e visando cumprir perspectivas e previsões de crescimento para a economia brasileira, seria natural a preocupação com uma relativa escassez de mão de obra.

1 Araújo et al. (2009) denominam como pessoal técnico-científico: pesquisadores, engenheiros, diretores e gerentes de pesquisa e desenvolvimento (P\&D) e profissionais 'científicos'.

2 Um mismatch de qualificação no mercado de trabalho pode ser entendido como um descompasso entre as habilidades dos trabalhadores que estão procurando por empregos e a qualificação demandada pelos empregadores (Faberman e Mazumder, 2012).

3 Para maiores informações, ver www.bls.gov. 
Para Teitelbaum (2004) seria razoável supor que um "apagão" de pessoal técnico-científico seria sinalizado por ao menos dois indicadores de mercado: i) forte pressão para cima nos salários reais; e ii) baixas taxas de desemprego - consideradas em i) e ii) ocupações com nível de escolaridade semelhante. Considerando o mecanismo de preços da economia, maiores salários atrairiam maior interesse dos jovens por essas profissões, e o problema da escassez tenderia a se reduzir. Contudo, no caso dos engenheiros, não constitui tarefa corriqueira precisar o grau de competitividade desse mercado, sobretudo porque a potencial substituição entre profissionais com diferentes habilitações é, em certa medida, limitada, principalmente quando são necessárias especialidades de oferta mais restritas, como engenharia naval, telecomunicações e geologia (Pompermayer et al., 2011).

Os receios de potenciais apagóes de mão de obra costumam decorrer de projeções futuras de demanda (Freeman, 2007; Teitelbaum, 2004), ainda que também seja possível encontrar estudos realizados para áreas específicas ${ }^{4}$ e pesquisas de campo que procuram retratar a situação atual segundo a visão do empresariado, como em pesquisas recentes da Confederação Nacional da Indústria (CNI, 2011).

A CNI (2011) empregou uma pesquisa de campo em janeiro de 2011 com 1.616 empresas brasileiras, sendo 931 pequenas, 464 médias e 221 grandes, a respeito da escassez de trabalho especializado na indústria e de seus possíveis impactos. Os resultados dessa pesquisa de opinião revelaram que, em média, 69\% das empresas industriais consultadas se deparam com dificuldades para encontrar trabalhadores especializados, sendo as empresas de pequeno e médio porte as mais prejudicadas. A área de produção foi a mais afetada, uma vez que $94 \%$ dessas empresas relataram dificuldades em encontrar técnicos, $82 \%$ em encontrar operadores e $61 \%$ evidenciaram a falta de engenheiros especializados. Em 25 dos 26 setores da indústria de transformação considerados na pesquisa, pelo menos a metade das empresas enfrenta a falta de trabalhador especializado, sendo os setores Vestuário, Outros equipamentos de transporte, Limpeza e perfumaria e Móveis aqueles em que o problema foi mais comum. Nesses setores, o percentual de empresas com dificuldades em encontrar mão de obra especializada superou o patamar de $80 \%$.

4 Estimativas nesse sentido já são realidade na área de tecnologia da informação (Villela, 2009) e para projetos de engenharia para produtos de transporte marítimo (Barros, 2004). 
Por outro lado, entre os estudos que procuraram realizar projeções de demanda e oferta futuras por engenheiros para diferentes cenários de crescimento econômico, como em Nascimento et al. (2010), Pereira e Araújo (2011) e Maciente e Araújo (2011), a visão prevalecente, tendo como horizonte o ano de 2022, nos dois primeiros estudos, e 2020, no último, é que não se vislumbra uma escassez generalizada, a não ser que o país cresça a taxas maiores que $5 \%$.

Contrastando dados de requerimento técnico ${ }^{5}$ por engenheiros com dados dos egressos dos cursos de engenharia, ${ }^{6}$ no período de 2003 a 2008, Nascimento et al. (2010) estimam o estoque total de engenheiros graduados no ano de 2008 para a economia brasileira. Os autores ressaltam que, para um crescimento real acumulado do PIB de $26,5 \%$, o requerimento técnico por engenheiros, arquitetos e profissionais correlatos no Brasil aumentou em 51,6\% entre 2003 e 2008, sendo um possível indicativo de que se trata de uma categoria profissional fortemente demandada em períodos de maior crescimento econômico. O número ${ }^{8}$ de egressos dos cursos de engenharia também apresentou forte expansão no período, apresentando crescimento acumulado de $106 \%$. O estoque total estimado de engenheiros graduados para o ano de 2008 foi de 750 mil profissionais, frente a um requerimento observado total de 211.713 profissionais.

Os autores chamam a atenção para um aspecto importante do mercado de trabalho dos engenheiros: nem todos os diplomados em engenharia vêm a ocupar no mercado de trabalho funções típicas da profissão. Para cada dois graduados em engenharia trabalhando atualmente com carteira assinada em ocupações típicas de sua formação, há outros cinco em uma das seguintes situações: exercem outras ocupações; estão desempregados; exercem atividades como profissionais não assalariados; emigraram para outros países; ou estão simplesmente fora do mercado de trabalho (Nascimento et al., 2010). Portanto, enfatizam que sempre haverá um estoque maior de engenheiros formados do que o de trabalhadores cuja ocupação seja

\footnotetext{
5 Nascimento et al. (2010) interpretam "requerimento técnico" como a quantidade de profissionais com esta competência profissional requerida tecnicamente para atender a um determinado nível de produção. Difere, pois, do conceito de demanda, que se refere à quantidade de profissionais que seriam empregados a um determinado nível de salários.

6 O Censo da Educação Superior define como Engenharia as áreas de formação pertencentes ao grupo Engenharia, Produção e Construção (INEP, 2011).

7 O dado de emprego foi obtido a partir da Relação Anual de Informações Sociais fornecida pelo Ministério do Trabalho e Emprego (Rais/TEM, 1986-2009).

8 Dados do Censo da Educação Superior.
} 
típica de engenheiro para atender as demandas em outros segmentos da estrutura de emprego.

Considerando essa restrição, Nascimento et al. (2010) ainda realizaram projeções sobre a oferta e demanda por engenheiros até o ano de 2020 em três cenários distintos de crescimento econômico, com taxas de crescimento de 3\%, 5\% e 7\% a.a., respectivamente. Os resultados apontam que, se a proporção atual de engenheiros que não trabalham na área fosse mantida, haveria escassez desses profissionais em todos os cenários. No entanto, com a elevação dos salários, os engenheiros que estivessem fora do mercado ou em outras funções seriam atraídos e, portanto, não se poderia falar em escassez, considerando a taxa de crescimento intermediária. Ou seja, os novos egressos em engenharia adicionados ao estoque atual de profissionais deste grupo seriam suficientes para sustentar a demanda por esse tipo de qualificação.

Por sua vez, Pereira e Araújo (2011) realizaram projeções para a oferta futura de engenheiros e profissionais afins até o ano de 2020, considerando diferentes ritmos de expansão no número de concluintes em cursos de ensino superior nestas áreas. Os resultados apontam que o mercado de trabalho brasileiro poderá contar, em 2020, com um estoque entre 1,5 e 1,8 milhão de pessoas formadas em engenharias - por instituições brasileiras de ensino superior - aptas a atuar em ocupações típicas da área. Os autores ressaltam algumas limitações de seu estudo, principalmente relacionadas às alterações no regime previdenciário não consideradas no trabalho.

Realizando projeções para a demanda por esse tipo de profissional, também para 2020, Maciente e Araújo (2011) desagregam sua análise para os setores econômicos. Os resultados mostram situação mais crítica em relação a uma relativa escassez de engenheiros para os setores de extração mineral (incluindo petróleo e gás), construção e infraestrutura. Portanto, salientam a relevância das análises setoriais quando se pensa em escassez de mão de obra. Essa é uma premissa importante na análise do impacto de restrições da oferta de trabalho especializado, pois a utilização dessa mão de obra varia consideravelmente entre setores da indústria, devido a características tecnológicas de produção distintas. 
Parece haver um consenso entre os estudos de que a hipótese de escassez de engenheiros e de um possível "apagão" deve ser vista com cuidado; no entanto, deve-se ter um olhar atento para o ritmo de formação destes profissionais na economia brasileira. Nesse sentido, os trabalhos ressaltam a necessidade de se melhorar a educação básica, para que os alunos desenvolvam maiores habilidades em relação às disciplinas exigidas em um curso de engenharia e sintam-se mais atraídos pela profissão. Outra preocupação é a melhoria da qualidade das Universidades, pois a criação de um número maior de vagas sem o respectivo cuidado com a qualidade dos cursos não resolveria o problema de escassez.

A partir dos elementos acima, pode-se argumentar que o crescimento do emprego e do nível de atividade no Brasil pode esbarrar na recente dificuldade de contratação de mão de obra especializada, como relatam diversos setores industriais e empresas. Essa relativa escassez de trabalho pode representar um obstáculo ao desenvolvimento econômico do país, e minorar os impactos benéficos de conjunturas favoráveis de crescimento e oportunidades de investimento. Nesse sentido, tornam-se relevantes estudos que procurem avaliar os possíveis impactos que uma limitação de mão de obra especializada impõe à economia brasileira.

Entre os estudos que tratam do tema para a economia nacional, nenhum deles teve como foco as inter-relações do sistema econômico, isto é, os possíveis efeitos sistêmicos encadeados por uma restrição na oferta de mão de obra qualificada, neste caso técnicos e engenheiros, perante um cenário de crescimento econômico. Projeções desse tipo são importantes na medida em que, ao considerar o sistema econômico como um todo, apontam como se daria a transmissão dos efeitos, permitindo acessar, além do impacto total sobre a economia, impactos específicos sobre as trajetórias dos agregados econômicos e setores, especialmente os da indústria. Tais informações são passíveis de serem analisadas a partir do emprego de um modelo de equilíbrio geral computável (EGC). Esses modelos tomam explicitamente a estrutura de interdependência entre os setores, permitindo projetar impactos de mudanças nos preços relativos, além de determinar o equilíbrio entre demanda e oferta mediante preços flexíveis (Domingues, 2002; Haddad, 2004). 
Entre as limitações comumente atribuídas aos modelos EGC, destacam-se aquelas relacionadas às hipóteses e formulações do modelo, como existência de concorrência perfeita, mobilidade perfeita de fatores, ausência de mercado monetário, racionamentos quantitativos e incertezas (Fochezatto, 2005). Especificamente sobre o mercado de trabalho, a premissa de ausência de substituição entre diferentes habilidades é a crítica mais comum. Contudo, o método é bastante apropriado às análises que objetivam captar os efeitos de transmissão entre os diferentes mercados integrados. Por exemplo, análises dos efeitos encadeados por uma possível restrição na oferta de pessoal especializado no mercado de trabalho sobre os diferentes setores produtivos seriam provavelmente insuficientes em uma abordagem de equilíbrio parcial.

Até recentemente o mercado de trabalho não configurava um dos principais focos de atenção na literatura de EGC (Boeters e Savard, 2013). Todavia, a tentativa de aprimorar sua modelagem, no intuito de flexibilizar as hipóteses adotadas, vem se popularizando na literatura internacional. Boeters e Savard (2013) destacam dois tipos de abordagem: $i$ ) estudos cujo foco recai sobre choques especificamente direcionados ao mercado de trabalho, que são predominantemente sobre estruturas tributárias, como em Sorensen (1997), Bohringer et al. (2005), Aaberg et al. (2004), Boeter (2010), Dixon et al. (2011); e ii) estudos que analisam políticas ou choques macroeconômicos não direcionados especificamente ao mercado de trabalho, mas que exercem impactos sobre emprego e sua distribuição, e que dependem, portanto, de suas especificações. São exemplos desse segundo grupo os trabalhos de Melo e Tarr (1992), Hérault (2007), Bourguignon e Savard (2008), Fraser e Waschik (2010), Robilliard et al. (2008). Em ambos os grupos, os autores buscam aprimoramentos na modelagem como a incorporação de heterogeneidade no mercado de trabalho, informalidade e integração com microssimulação.

Na literatura nacional de modelos EGC, o desenvolvimento da modelagem do mercado de trabalho é menos presente. As aplicações de modelos EGC, independente do foco ou não no mercado de fatores, usualmente desagregam o trabalho pelo nível educacional ou salarial, permitindo captar heterogeneidades entre mão de obra qualificada e não qualificada. São exemplos os estudos de Ferreira Filho e Horridge (2006) e Cury e Leme (2007). Recentemente, trabalhos como o de Bitencourt e Teixeira (2008), Souza e Domingues (2014), 
Souza, Cardoso e Domingues (2016) e Souza (2015) realizaram análises específicas a partir de modelos EGC sobre o mercado de trabalho brasileiro. Bitencourt e Teixeira (2008) avaliaram os efeitos de reduções dos encargos sociais sobre os indicadores macroeconômicos considerando a divisão usual entre trabalho qualificado e não qualificado. Em Souza, Cardoso e Domingues (2016) o foco recai sobre a análise dos efeitos da política de desoneração da folha de salários proposta pelo Governo Dilma Rousseff em seu primeiro mandato. Já Souza e Domingues (2014) e Souza (2015) inovam no estudo de questões do mercado de trabalho brasileiro. O primeiro avalia os impactos do ganho salarial do trabalho doméstico e, o segundo, sobre discriminação de gênero.

Esses trabalhos, entretanto, não contam com uma desagregação por nível ocupacional que permita análises específicas da dinâmica do mercado quanto à trajetória da oferta de pessoal especializado, nos moldes de como esse fenômeno vem sendo discutido no atual cenário econômico. Com vistas a preencher essa lacuna, este artigo emprega o BRIDGE (Brazilian Recursive Dynamic General Equilibrium Model), ${ }^{9}$ modelo EGC especialmente configurado para analisar efeitos da escassez de trabalho especializado, especificamente engenheiros e técnicos, nas trajetórias de crescimento da economia brasileira e dos setores industriais. O fator trabalho neste modelo está desagregado em cinco ocupações: engenheiros, técnicos, gerentes, diretores e demais ocupações. É importante ressaltar, ainda, que elementos de dinâmica recursiva são incorporados ao mercado de trabalho, tendo em vista que o mesmo apresenta certa inércia no comportamento dos salários e do emprego.

O artigo está organizado em mais três seções, além desta introdução. A seção 2 apresenta o modelo e a base de dados utilizada na análise do problema em tela. A seção 3 discute as simulações e os resultados obtidos. A seção 4 tece as considerações finais.

9 O modelo BRIDGE (Domingues et al., 2014) foi desenvolvido como parte das atividades do Núcleo de Estudos em Modelagem Econômica Aplicada (NEMEA) do CEDEPLAR/UFMG. O grupo conta com a participação de professores e alunos da pós-graduação no CEDEPLAR, sob a coordenação do Prof. Dr. Edson Paulo Domingues. 


\section{Modelo e base de dados}

A Tabela 1 resume a utilização de trabalhadores por ocupação em três setores econômicos amplos para uma análise comparativa. Os dados referem-se a 2010 e foram obtidos a partir das informações da Relação Anual de Informações Sociais (RAIS). Os números revelam a concentração da utilização de engenheiros na indústria (62\%) e de Técnicos no setor de serviços (61\%). O setor de serviços também concentra a utilização de Diretores e Gerentes, embora a participação destes no uso de trabalho seja inferior a $6 \%$ dos pagamentos do setor. Por seu turno, a remuneração de Técnicos representa $10,7 \%$ dos pagamentos de trabalho da indústria, e a de Engenheiros, cerca de $4 \%$.

Tabela 1 - Distribuição das Ocupações por Setor de Atividade, Brasil, 2010

\begin{tabular}{|c|c|c|c|c|c|c|}
\hline Grandes setores & Engenheiros & Técnicos & Diretores & Gerentes & Outros & Total \\
\hline \multicolumn{7}{|c|}{ Remunerações do trabalho ( $R$ \$ bilhões) } \\
\hline Agropecuária & 0,3 & 1,1 & 0,2 & 1,4 & 42,2 & 45 \\
\hline Indústria & 9,5 & 22,8 & 3,7 & 14,6 & 161,6 & 212 \\
\hline Serviços & 5,4 & 37,0 & 9,2 & 29,3 & 518,0 & 599 \\
\hline Total & 15,2 & 60,9 & 13,1 & 45,3 & 721,8 & 856 \\
\hline \multicolumn{7}{|c|}{ Distribução (\%) por setor } \\
\hline Agropecuária & 0,7 & 2,4 & 0,5 & 3,2 & 93,2 & 100 \\
\hline Indústria & 4,5 & 10,7 & 1,7 & 6,9 & 76,2 & 100 \\
\hline Serviços & 0,9 & 6,2 & 1,5 & 4,9 & 86,5 & 100 \\
\hline Total & 1,8 & 7,1 & 1,5 & 5,3 & 84,3 & 100 \\
\hline \multicolumn{7}{|c|}{ Distribuição (\%) por ocupação } \\
\hline Agropecuária & 2,1 & 1,8 & 1,6 & 3,2 & 5,9 & 5,3 \\
\hline Indústria & 62,4 & 37,4 & 28,3 & 32,2 & 22,4 & 25 \\
\hline Serviços & 35,6 & 60,8 & 70,1 & 64,7 & 71,8 & 70 \\
\hline Total & 100 & 100 & 100 & 100 & 100 & 100 \\
\hline
\end{tabular}

Fonte: Núcleo de dados do Modelo com base nos dados da RAIS (2010).

A Tabela 2 apresenta a composição das remunerações pagas por tipo de ocupação em cada setor industrial, bem como fornece as participações do trabalho e capital no valor adicionado (VA) de tais atividades industriais. As informações contidas para cada setor permitem caracterizá-los, ou seja, indicar se os mesmos são mais intensivos em capital ou trabalho e quais tipos de ocupações são predominantes nas estruturas de custos. Setores como Petróleo e gás natural, Minério de ferro, Refino de petróleo e coque, Álcool, Fabricação de resina e elastômeros, Cimento, Fabricação de aço e derivados e Eletricidade, gás, água, esgoto, limpeza podem ser considerados como os mais 
intensivos em capital. Desses setores citados, apenas Refino de petróleo e coque apresenta uma participação maior de engenheiros na remuneração total de trabalho (30,3\%) quando comparado com a de técnicos. Assim, apesar da possibilidade de substituição imperfeita entre capital e trabalho, espera-se que esse setor venha a enfrentar uma queda no seu nível de produção em virtude da restrição de oferta de engenheiros no mercado de trabalho, desencadeando efeitos negativos sobre a demanda no mercado de insumos no sistema produtivo brasileiro, assim como na elevação dos custos de produção. Com a diminuição do nível de produção, o setor passaria a requisitar menos capital e trabalho no seu processo produtivo, o que levaria a queda na rentabilidade do capital, nas taxas de retorno e nos investimentos neste setor.

Esses mecanismos e principais relações causais subjacentes à restrição de oferta de engenheiros seriam semelhantes para uma similar restrição ao mercado de técnicos. Entretanto, haveria um efeito mais amplo oriundo da restrição de técnico. Na maioria dos setores mais intensivos em capital, como já supracitados, há uma maior participação de técnicos em relação aos engenheiros dentro do valor total de trabalho, o que acentuaria a queda da atividade econômica na economia brasileira, gerando maiores perdas de competitividade dos produtos domésticos perante a elevação generalizada dos custos e, portanto, afetando de forma mais intensa o volume exportado do país. Setores industriais como Petróleo e Gás e Mineiro de Ferro apresentam uma significativa participação na pauta exportadora (acima de 3,2\%).

Por outro lado, de acordo com a Tabela 2, os setores mais intensivos em trabalho seriam a atividades de Couro e calçados, Máquinas e equipamentos, Escritório e informática, Material eletrônico e comunicações, Caminhões e ônibus, Peças e acessórios para veículos e Outros equipamentos de transporte (participação acima de $65 \%$ no VA). Em todas essas atividades industriais, há uma predominância de técnicos dentro da remuneração do trabalho, quando também comparados com a participação de engenheiros. Portanto, os efeitos adversos da restrição de técnicos sobre o sistema produtivo brasileiro seriam mais intensos e transmitidos por um número maior de canais, pois tanto os setores intensivos em trabalho como em capital revelam, em geral, uma maior participação de técnicos. Cabe ressaltar que os técnicos são mais demandados na indústria de produtos farmacêuticos e na extração de Petróleo e Gás Natural, cuja partici- 
pação no total de remunerações pagas chega a 21,37 e 10,94\%, respectivamente. Para diretores e gerentes há maior homogeneidade na distribuição de remunerações entre os setores, mas possuem participação acima da média em atividades como Produtos Farmacêuticos, Produtos e Preparos de Químicos Diversos e Defensivos Agrícolas, entre outras.

Tabela 2 - Participações selecionadas na estrutura de custos industriais (2005)

\begin{tabular}{|c|c|c|c|c|c|c|c|}
\hline \multirow{2}{*}{ Setores indústriais } & \multicolumn{5}{|c|}{ Composição (\%) nas remunerações trabalhistas } & \multicolumn{2}{|c|}{ Part. $(\%)$ no $V A^{(1)}$} \\
\hline & Engenheiros & Tecnicos & Diretores & Gerentes & Outros & Trabalho & Capital \\
\hline Petróleo e gás natural & 15,3 & 21,7 & 1,2 & 5,6 & 56,3 & 23,4 & 75,5 \\
\hline Minério de ferro & 9,5 & 18,3 & 4,4 & 13,2 & 54,6 & 12,4 & 85,9 \\
\hline Outros da indústria extrativa & 4,4 & 10,0 & 1,6 & 6,3 & 77,7 & 40,1 & 52,7 \\
\hline Alimentos e Bebidas & 0,8 & 5,9 & 1,5 & 6,9 & 84,8 & 49,2 & 43,4 \\
\hline Produtos do fumo & 0,4 & 16,1 & 2,4 & 19,9 & 61,2 & 50,0 & 45,8 \\
\hline Têxteis & 0,4 & 6,1 & 1,4 & 5,3 & 86,7 & 39,7 & 45,1 \\
\hline Vestuário e acessórios & 0,1 & 2,7 & 0,3 & 4,3 & 92,7 & 51,3 & 6,0 \\
\hline Couro e calçados & 0,1 & 3,0 & 0,3 & 3,0 & 93,6 & 77,4 & 15,0 \\
\hline Produtos de madeira (exceto móveis) & 0,6 & 3,2 & 0,9 & 5,2 & 90,0 & 48,1 & 41,8 \\
\hline Celulose e produtos de papel & 2,2 & 11,3 & 2,7 & 9,9 & 73,9 & 50,0 & 46,5 \\
\hline Jornais, revistas, discos & 0,3 & 7,7 & 2,8 & 7,8 & 81,3 & 42,9 & 48,9 \\
\hline Refino de petróleo e coque & 30,3 & 14,5 & 0,3 & 1,0 & 54,0 & 24,4 & 71,2 \\
\hline Álcool & 1,9 & 5,1 & 1,2 & 3,4 & 88,4 & 22,7 & 75,9 \\
\hline Produtos químicos & 7,0 & 14,9 & 3,7 & 15,5 & 58,9 & 43,5 & 52,4 \\
\hline Fabricação de resina e elastômeros & 7,2 & 19,4 & 3,8 & 12,5 & 57,0 & 30,8 & 66,1 \\
\hline Produtos farmacêuticos & 1,4 & 30,6 & 5,1 & 18,3 & 44,7 & 41,7 & 56,1 \\
\hline Defensivos agrícolas & 6,9 & 18,8 & 4,5 & 18,6 & 51,1 & 45,3 & 50,6 \\
\hline Perfumaria, higiene e limpeza & 1,3 & 10,6 & 2,9 & 12,1 & 73,2 & 38,0 & 58,7 \\
\hline Tintas, vernizes, esmaltes e lacas & 1,8 & 17,1 & 3,6 & 13,4 & 64,1 & 56,8 & 39,8 \\
\hline Químicos diversos & 3,4 & 14,4 & 5,1 & 18,4 & 58,8 & 58,2 & 37,0 \\
\hline Artigos de borracha e plástico & 1,4 & 10,5 & 1,7 & 7,1 & 79,2 & 60,0 & 35,2 \\
\hline Cimento & 4,4 & 18,3 & 3,1 & 13,5 & 60,8 & 29,6 & 67,9 \\
\hline Outros minerais não-metálicos & 1,2 & 5,4 & 1,1 & 5,5 & 86,7 & 57,8 & 36,5 \\
\hline Fabricação de aço e derivados & 6,0 & 17,8 & 2,5 & 8,4 & 65,2 & 29,6 & 67,7 \\
\hline Metalurgia de metais não-ferrosos & 3,5 & 11,4 & 1,8 & 6,3 & 77,0 & 34,9 & 62,4 \\
\hline Produtos de metal & 1,7 & 8,4 & 1,0 & 4,7 & 84,2 & 40,3 & 50,4 \\
\hline Máquinas e equipamentos & 4,3 & 12,4 & 1,9 & 7,8 & 73,6 & 68,8 & 26,2 \\
\hline Eletrodomésticos & 3,9 & 11,8 & 1,8 & 5,9 & 76,5 & 63,0 & 33,2 \\
\hline Escritório e informática & 4,1 & 14,8 & 3,6 & 12,9 & 64,7 & 66,7 & 28,8 \\
\hline Equipamentos e materiais elétricos & 6,9 & 12,1 & 2,6 & 11,2 & 67,2 & 51,8 & 44,5 \\
\hline Material eletrônico e comunicações & 6,9 & 15,5 & 2,7 & 10,5 & 64,5 & 77,5 & 16,8 \\
\hline Material hospitalar; medida e óptico & 4,4 & 14,8 & 3,1 & 10,8 & 66,9 & 34,5 & 56,2 \\
\hline Automóveis, camionetas e utilitários & 9,9 & 9,8 & 2,4 & 6,5 & 71,4 & 23,4 & 58,9 \\
\hline Caminhões e ônibus & 5,5 & 18,2 & 1,9 & 5,2 & 69,2 & 87,3 & 5,8 \\
\hline Peças e acessórios para veículos & 3,8 & 11,7 & 2,2 & 6,3 & 76,0 & 65,1 & 30,8 \\
\hline Outros equipamentos de transporte & 12,1 & 13,5 & 1,9 & 6,4 & 66,1 & 70,7 & 24,6 \\
\hline Móveis e indústrias diversas & 0,3 & 4,2 & 0,8 & 5,6 & 89,1 & 39,7 & 42,9 \\
\hline Eletricidade, gás, água, esgoto, limpeza & 10,8 & 15,5 & 1,6 & 4,6 & 67,5 & 20,9 & 77,6 \\
\hline Construção civil & 4,9 & 6,9 & 0,5 & 2,5 & 85,1 & 31,6 & 44,3 \\
\hline Total da indústria & 4,5 & 10,7 & 1,7 & 6,9 & 76,2 & 39,3 & 51,5 \\
\hline
\end{tabular}

Fonte: Núcleo de dados do Modelo com base nos dados da RAIS (2010).

(1) Valor Adicionado. 
Estes dados reafirmam a necessidade de uma análise setorial no estudo da demanda por trabalho especializado, pois existem características tecnológicas distintas entre os setores industriais que se refletem no uso das ocupações. Além disso, os setores não podem ser tomados de forma isolada, pois repercussões de escassez de trabalho especializado se difundem pelas cadeias produtivas e afetam todos os setores da economia. Assim, uma análise em equilíbrio geral torna-se particularmente adequada, pois a inter-relação setorial é tomada explicitamente, além das características diferenciadas do uso de trabalho pelos setores.

O modelo EGC utilizado neste trabalho está calibrado para o ano de 2005, utilizando as informações das matrizes de insumo-produto disponibilizadas pelo IBGE. Para este trabalho, o modelo foi configurado para 60 setores, 117 produtos, cinco componentes da demanda final (consumo das famílias, consumo do governo, investimento, exportações e estoques), dois elementos de fatores primários (capital e trabalho, este último subdividido em cinco ocupações) e dois setores de margens (comércio e transportes). Algumas características do modelo são importantes para sua utilização na temática do uso de trabalho especializado. O fator trabalho foi desagregado em cinco ocupações: engenheiros, técnicos, gerentes, diretores e demais ocupações. ${ }^{10}$

A especificação do modelo BRIGE baseia-se na tradição australiana em modelos EGC, principalmente nos modelos ORANI (Dixon et al., 1982) e MONASH (Dixon e Rimmer, 2002). Especialmente importantes são os elementos de dinâmica recursiva presentes no modelo, ${ }^{11}$ tanto no mecanismo de acumulação do estoque de capital como no ajuste do mercado de trabalho, que apresenta certa inércia no comportamento dos salários e do emprego. ${ }^{12}$ Neste trabalho, é de particular interesse a especificação da função de produção dos setores e o uso do trabalho por ocupação.

${ }^{10}$ Além disso, cinco tipos de tributos (IPI, ICMS, COFINS, INSS e FGTS) estão especificados individualmente, incidindo sobre fluxos de compras (IPI, ICMS), remuneração do trabalho (INSS e FGTS) e produção (COFINS). Esta especificação da base de dados e da estrutura teórica do modelo permite projetar políticas de desoneração de impostos por tributo, setor e tipo de trabalho por ocupação.

${ }^{11}$ Modelos EGC com dinâmica recursiva não são novos na literatura brasileira. Ver, por exemplo, Domingues et al. (2014), Hasegawa (2003), Haddad e Domingues (2001) e Fochezatto e Souza (2000).

12 O Anexo I detalha o funcionamento do mercado de trabalho. 
A Figura 1 apresenta a estrutura da função de produção dos setores. Os setores produtivos minimizam custos de produção sujeitos a uma tecnologia de retornos constantes de escala, em que a combinação de insumos intermediários e fator primário (agregado) são determinados por coeficientes fixos (Leontief). Na composição dos insumos há substituição via preços entre produto doméstico e importado, por meio de funções de elasticidade de substituição constante (CES).

Na composição dos fatores primários também há substituição via preço entre capital e trabalho (agregado) por funções CES. O fator trabalho é uma composição dos cinco tipos de ocupação, em proporções fixas (Leontief). Assim, não ocorre substituição entre tipos de ocupação via preços; o uso de qualquer ocupação varia proporcionalmente à utilização do fator trabalho. Esta especificação se justifica, pois não há na literatura informações sobre a possibilidade de substituição entre engenheiros e técnicos no processo produtivo. Além disso, o mais natural é que esta composição seja mantida fixa mesmo com alterações de preço relativo do trabalho, ou alterações no nível de atividade do setor.

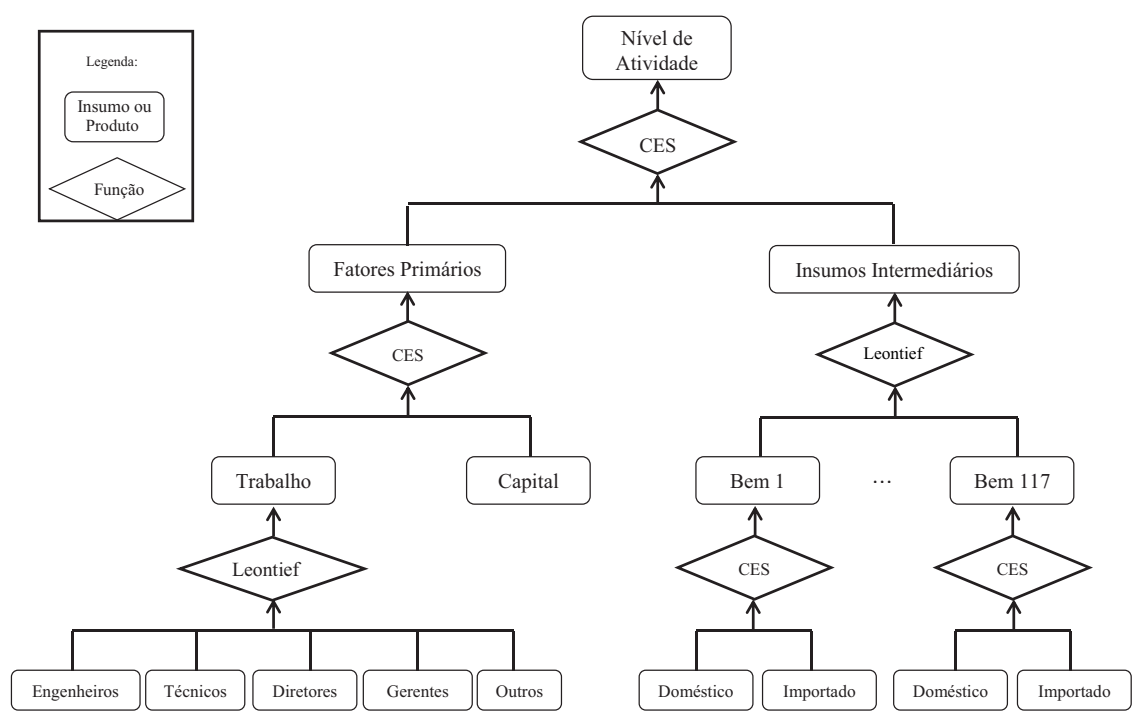

Figura 1 - Estrutura hierárquica da função de produção setorial

As famílias, por sua vez, estão desagregadas de acordo com decis de renda obtidos a partir dos dados da Pesquisa de Orçamento Familiar (POF) referente à 2002/2003 do IBGE (IBGE, 2004). 
Deles obtém-se a classificação das famílias por faixa de renda mensal, $\mathrm{i}=1,2, \ldots, 10$, mensurada por unidade de consumo. Em seguida, foram criadas as frações de renda consumida para cada item da matriz, para as dez famílias representativas por decil de renda. A Tabela 3 retrata as principais características dos decis de renda pela POF 2002-2003.

A demanda das famílias é especificada a partir de uma função de utilidade não homotética de Stone-Geary (Peter et al., 1996). Essa especificação divide o consumo dos bens e serviços em parcelas de "luxo" e "subsistência", reservando uma parcela fixa do gasto em subsistência e uma parcela residual em "gasto de luxo", o que permite que modificações na renda causem modificações diferenciadas no consumo dos produtos, daí seu caráter não homotético. $\mathrm{Na}$ composição do consumo do produto entre doméstico e importado, utilizam-se funções de elasticidade de substituição constante (CES).

Tabela 3 - Características dos decis de renda no Brasil pela POF 2002-2003.

\begin{tabular}{ccccccc}
\hline Decil & $\begin{array}{c}\text { Número de } \\
\text { observações }\end{array}$ & $\begin{array}{c}\text { População } \\
\text { correpondente }\end{array}$ & $\begin{array}{c}\text { Renda } \\
\text { Média }(\mathrm{R} \$)\end{array}$ & $\begin{array}{c}\text { Desvio } \\
\text { Padrão }(\mathrm{R} \$)\end{array}$ & $\begin{array}{c}\text { Mínimo } \\
(\mathrm{R} \$)\end{array}$ & $\begin{array}{c}\text { Máximo } \\
(\mathrm{R} \$)\end{array}$ \\
\hline 1 & 6.730 & 4.877 .783 & 210,71 & 68,96 & 4,00 & 305,00 \\
2 & 6.158 & 4.836 .322 & 379,11 & 43,59 & 306,00 & 453,00 \\
3 & 5.606 & 4.869 .806 & 523,81 & 40,63 & 454,00 & 596,00 \\
4 & 5.190 & 4.846 .089 & 674,80 & 47,17 & 597,00 & 758,00 \\
5 & 4.921 & 4.843 .652 & 859,31 & 60,67 & 759,00 & 970,00 \\
6 & 4.390 & 4.861 .636 & 1103,00 & 80,07 & 971,00 & 1246,00 \\
7 & 4.225 & 4.847 .143 & 1431,09 & 115,03 & 1247,00 & 1652,00 \\
8 & 3.972 & 4.845 .858 & 1954,89 & 195,15 & 1653,00 & 2341,00 \\
9 & 3.687 & 4.853 .007 & 3000,83 & 441,40 & 2342,00 & 3878,00 \\
10 & 3.689 & 4.853 .342 & 8000,76 & 6617,35 & 3881,00 & 385250,00 \\
\hline
\end{tabular}

Fonte: Elaboração própria a partir de dados da POF 2002/2003 (IBGE, 2012).

As exportações setoriais respondem a curvas de demanda negativamente associadas aos custos domésticos de produção e positivamente afetadas pela expansão exógena da renda internacional, adotando-se a hipótese de país pequeno no comércio internacional. O consumo do governo é tipicamente exógeno, podendo estar associado ou não ao consumo das famílias ou à arrecadação de impostos. Os estoques se acumulam de acordo com a variação da produção. 
O investimento e o estoque de capital seguem mecanismos de deslocamento intersetorial e de acumulação a partir de regras preestabelecidas, associadas a taxas esperadas de retorno e de depreciação do estoque de capital. Assim, setores com elevação na taxa esperada de retorno, calculada endogenamente, atraem investimento. Este investimento realizado no período $t$ gera o estoque de capital no período $t+1$ por meio de uma regra padrão de acumulação, a partir do estoque de capital inicial descontado da depreciação.

O mercado de trabalho também apresenta um elemento de ajuste intertemporal, que envolve as variáveis como o salário real, emprego atual e emprego tendencial por ocupação. Nesse mecanismo, o salário real se eleva relativamente ao cenário tendencial, sendo a taxa proporcional ao desvio entre o crescimento da oferta de trabalho e do emprego. O ajuste do salário real a esse gap entre oferta e demanda de trabalho é controlado por um parâmetro de ajustamento. No presente modelo este parâmetro foi calibrado de forma que o desvio do emprego decorrente de choque na economia é eliminado em aproximadamente 10 anos. $\mathrm{Na}$ próxima sessão, são apresentadas as simulações com o modelo.

\section{Simulações e resultados}

Os mecanismos de dinâmica recursiva permitem a utilização explicitamente temporal do modelo EGC, em que as variáveis endógenas se ajustam ao longo do período de análise após um choque inicial, como uma restrição de oferta de trabalho para uma ocupação específica. No caso deste trabalho, são apresentadas três simulações. A primeira é um cenário macroeconômico observado de 2006 a 2010; a segunda um cenário de restrição na oferta de trabalho de Engenheiros; e a terceira uma restrição na expansão da oferta de trabalho de Técnicos. Os objetivos dessas simulações são projetar o comportamento de uso do fator trabalho no cenário econômico recente (2006-2010) e como as restrições de oferta de trabalho em ocupações especializadas (Técnicos e Engenheiros) impactam na economia brasileira, em especial nos setores industriais, em um cenário 2011-2020. As demais ocupações utilizadas no modelo (diretores e gerentes) não serão foco de análise neste trabalho por representarem especialidades mais heterogêneas e relativamente menos utilizadas pelos setores industriais. 
Nas simulações de restrição de oferta de trabalho especializado, os resultados representam um desvio em relação ao cenário de referência para o período 2011-2020. Esse cenário estabelece uma taxa de crescimento de $4,5 \%$ para a economia brasileira, homogênea para todos os setores de atividade e variáveis reais da economia, inclusive na oferta de todos os tipos de trabalho. Assim, não há deslocamento relativo da produção entre setores, nem alterações de preços relativos. Com a inclusão dos choques de restrição de oferta de trabalho, o modelo pode calcular o impacto desse fenômeno nos setores e nos agregados macroeconômicos. Todas as simulações foram realizadas no software RunDynam. ${ }^{13} \mathrm{O}$ Quadro 1 resume as simulações realizadas com o modelo.

Na operacionalização de modelos EGC, uma questão relevante são suas hipóteses de simulação, ou o conjunto de variáveis exógenas e endógenas, problema conhecido como "fechamento" do modelo. Com a especificação de dinâmica recursiva, dois problemas usuais de fechamento, oferta de trabalho e de capital são resolvidos pelas especificações de ajuste no mercado de trabalho e de acumulação de capital.

Explorando a capacidade recursiva do modelo, a análise é efetuada a partir de dois fechamentos: base e de política. O fechamento base estabelece um conjunto de choques e uma escolha de variáveis endógenas de forma a reproduzir um cenário de referência para a análise. Neste caso, as variáveis do PIB, Investimento, Consumo das Famílias, Gastos do Governo, Emprego Tendencial, Número de Famílias, Demanda por Exportações (por produto) e Preço das Importações (por cada produto) são colocadas como exógenas, e seus valores seguem as variações percentuais reais observadas (2006-11) ou projetadas (2012-20). Assim, entre 2006 a 2011, essas variáveis tomam os valores observados no período, retirados das Contas Nacionais (IBGE,2004). Como o modelo é dinâmico, esses choques são aplicados anualmente. Os dados de exportações e preços das importações são retirados do sistema ALICEWEB do Secex e compatibilizados com os setores do modelo.

${ }^{13}$ O RunDynam é um aplicativo customizado do Gempack 10.0 (Harrison e Pearson, 2002) para simulações de dinâmica recursiva e modelos intertemporais. Maiores detalhes em https://www.vu.edu.au/centre-of-policy-studies-cops. Na versão utilizada neste trabalho, o modelo condensado utilizado aqui possui 3430 equações e 8775 variáveis. 
Quadro 1 - Resumo das simulações, fechamento e instrumentos de política

\begin{tabular}{lclc}
\hline Simulações & Fechamento & \multicolumn{1}{c}{ Choques } & Período \\
\hline Cenário 2006-2010 & Base & $\begin{array}{l}\text { Agregados observados: PIB, Consumo das } \\
\text { Famílias, Exportações e Investimento. }\end{array}$ & 2006-2010 \\
Cenário 2011-2020 & Base & $\begin{array}{l}\text { Cenário homogêneo: PIB, Consumo das } \\
\text { Familias, Investimento e Importações cres- } \\
\text { cem 4,5\% a.a.. }\end{array}$ & 2011-2020 \\
Restrição em Engenheiros & Politica & $\begin{array}{l}\text { Queda na oferta de engenheiros de 0,5\% a.a. } \\
\text { em relação ao cenário base. }\end{array}$ & 2011-2020 \\
Restrição em Técnicos & Politica & $\begin{array}{l}\text { Queda na oferta de técnicos de 0,5\% a.a. em } \\
\text { relação ao cenário base. }\end{array}$ & 2011-2020 \\
\hline
\end{tabular}

Fonte: Elaboração própria.

A partir de 2012, todos esses indicadores crescem a 4,5\% ao ano, exceto o preço das importações, que aumenta em $2 \%$ ao ano. Além dessas variáveis, são consideradas exógenas as mudanças tecnológicas, tais como a produtividade dos fatores primários (trabalho e capital), assim como a preferência das famílias, a taxa de retorno normal e a razão do investimento pelo capital. As demais variáveis foram definidas endógenas.

O fechamento de política estabelece diferentes status para variáveis endógenas e exógenas relativas ao cenário básico da economia, além dos choques da política (no caso, a restrição de oferta de trabalho especializado). Estes choques causam desvios nas variáveis endógenas tanto no ano inicial como posteriormente, efeito desencadeado pelas alterações de preços relativos e quantidades reais no ano inicial e aos mecanismos recursivos (acumulação de capital e ajuste no mercado de trabalho). Especificamente, o choque de política simulado é na variável de emprego de técnicos e engenheiros, que representa o choque de restrição na oferta dessas ocupações.

\subsection{Simulações do cenário 2006-2010}

O primeiro conjunto de simulações refere-se ao quadro macroeconômico observado entre 2006 e 2010. Aproveitando as características de dinâmica recursiva do modelo, foi estabelecido um fechamento de cenário que permite decompor, para todas as variáveis econômicas 
do modelo, as repercussões do cenário macroeconômico observado. O foco são os resultados setoriais para a indústria e a utilização de trabalho por ocupação. Este exercício de simulação procura utilizar a estrutura do modelo EGC para explicitar como os condicionantes macroeconômicos repercutem na dinâmica da utilização dos diferentes tipos de trabalho na economia e nos setores industriais. Este exercício difere de estudos econométricos, pois toma explicitamente a relação intersetorial e os condicionantes macroeconômicos. Por outro lado, a aderência estatística das simulações não está garantida, uma vez que se trata de um modelo determinístico.

Assim, os números da Tabela 4 representam tanto os aspectos do cenário macroeconômico observado no período como o vetor de choques em variáveis exógenas do modelo EGC no fechamento base. Para cada variável exógena, uma variável endógena é escolhida, de forma que o cenário possa ser efetivamente simulado no modelo. Diante dos indicadores observados entre 2006 e 2010, nota-se que a crise financeira desencadeada a partir do segundo semestre de 2008 significou uma inflexão da trajetória de crescimento da economia brasileira, que entre 2006 e 2008 cresceu a uma taxa média anual de cerca de 5\%. O crescimento do PIB em 2009 foi negativo, $-0,19 \%$, com forte retração dos investimentos $(-17,51 \%)$. Os números mostram que o consumo das famílias ${ }^{14}$ e do governo foram os componentes menos afetados pela crise, com taxas de crescimento de $4,05 \%$ e 3,69\%, respectivamente, embora a base de comparação para estes componentes seja menor, dado que apresentam um crescimento menos dinâmico frente ao período de 2006 a 2008. Em 2010, a economia se recuperou, com expansão de $7,5 \%$ do PIB, impactado expressivamente pela expansão do investimento $(21,8 \%)$.

O comportamento dos componentes do PIB, ao longo do período 2006-2010, impacta de forma diferenciada no nível de atividade setorial, condicionado pela composição da demanda setorial, pelas cadeias produtivas, modificações de preços relativos e intensidade no uso de fatores produtivos.

\footnotetext{
${ }^{14}$ No modelo, não há uma conexão explícita entre remuneração dos fatores e o consumo das famílias (renda). Essa ligação é resolvida pelo fechamento do modelo, pois o consumo das famílias se move endogenamente para equilibrar as variações do PIB do lado da renda (remunerações de capital e trabalho) e do lado do dispêndio (ver Horridge (2006)). Dessa forma, modificações na composição dos trabalhadores afetam a renda agregada, que por sua vez afeta igualmente o consumo das famílias de forma proporcional a suas rendas iniciais.
} 
Tabela 4 - Indicadores macroeconômicos, Brasil 2006-2010 (var \% real a.a.)

\begin{tabular}{lccccc}
\hline Variáveis & 2006 & 2007 & 2008 & 2009 & 2010 \\
\hline PIB & 3,96 & 6,09 & 5,14 & $-0,19$ & 7,51 \\
Consumo das Famílias & 5,20 & 6,30 & 5,38 & 4,05 & 7,00 \\
Investimento & 10,41 & 13,96 & 16,96 & $-17,51$ & 21,80 \\
Consumo do Governo & 2,58 & 4,73 & 5,64 & 3,69 & 3,30 \\
Exportações & 3,31 & 5,50 & $-2,46$ & $-10,79$ & 11,50 \\
Importações & 6,87 & 8,24 & 22,01 & $-10,54$ & 36,20 \\
\hline
\end{tabular}

Fonte: IBGE, IPEA e FUNCEX.

A vantagem do uso de um modelo EGC é que estes aspectos são tomados explicitamente, na base de dados e na especificação do modelo, para o resultado do impacto do cenário sobre a atividade econômica setorial, e, por conseguinte, no uso dos fatores produtivos, como a mão de obra de Engenheiros e Técnicos. Assim, o entendimento das projeções do uso destes tipos de trabalho no cenário 2006-2010 deve partir da análise dos resultados setoriais, em termos de quais setores foram mais (e menos) dinâmicos no período.

O cenário macroeconômico, seu impacto setorial, e as relações nas cadeias produtivas determinam o resultado do cenário sobre o uso de trabalho por ocupações, apresentado na Tabela 5.

Tabela 5 - Expansão do PIB e projeções de emprego por ocupação (var \% a.a.)

\begin{tabular}{lccccc}
\hline Variáveis & 2006 & 2007 & 2008 & 2009 & 2010 \\
\hline PIB & 3,80 & 6,00 & 5,10 & $-0,20$ & 7,50 \\
Emprego Técnicos & 6,50 & 7,40 & 5,80 & $-1,40$ & 8,40 \\
Emprego Engenheiros & 7,90 & 8,90 & 6,30 & $-8,30$ & 11,60 \\
Emprego Diretores & 5,70 & 6,70 & 5,30 & 1,00 & 6,80 \\
Emprego Gerentes & 6,20 & 7,30 & 5,30 & $-1,30$ & 8,70 \\
Emprego Outros & 6,10 & 7,00 & 6,70 & 0,40 & 6,80 \\
\hline Emprego Total & 6,10 & 7,10 & 6,50 & 0,10 & 7,10 \\
\hline
\end{tabular}

Fonte: Resultados das simulações. 
Em geral, o uso de Engenheiros cresceria acima da média das demais ocupações, principalmente em 2010 (11,6\%). A composição do investimento e seu crescimento mais acelerado nestes anos explicam este resultado: setores intensivos na composição do investimento e que utilizam mais engenheiros em sua produção (tais como construção civil e bens de capital) apresentariam um aumento maior no nível de atividade. Logo, o aquecimento no nível de atividade destes setores implicaria maior crescimento projetado de emprego para esta ocupação. O ano de 2009, como esperado, destoa dos demais em razão da crise econômica, verificando-se uma queda expressiva do uso de engenheiros no ano $(-8,3 \%)$, também condicionado pela retração do investimento.

Na utilização de todas as ocupações, as oscilações no cenário de emprego (Tabela 4) se devem ao comportamento do PIB, definido exogenamente no cenário base com dados observados da economia, além da participação das ocupações nos setores do modelo. Dessa forma, entende-se que o aumento no uso de técnicos na economia é mais intenso porque os setores que apresentam a maior participação relativa dessa ocupação crescem de forma mais acentuada. Em geral, na folha de pagamento do setor industrial existe uma predominância de técnicos (conforme a Tabela 2, uma média de 10,7\%). Essa maior dispersão do uso de técnicos tende a suavizar o impacto do ciclo econômico na utilização desse tipo de trabalho, o que não ocorre com Engenheiros, muito concentrado em alguns setores que são influenciados pela dinâmica do investimento. Pode-se notar isso de forma mais evidente, no resultado para o ano da crise econômica de 2009, onde houve uma retração da economia, com uma redução mais significativa no investimento. Nesse ano, a economia brasileira registrou uma queda no nível de atividade (capturado pelos choques do cenário básico) e, por consequência, uma retração maior na utilização de engenheiros.

A fim de sintetizar os resultados acima, foram calculadas "elasticidades implícitas" de cada ocupação, isto é, a relação entre a variação do emprego e a variação do PIB (Tabela 6). ${ }^{15}$ Em geral, as elasticidades são superiores a 1 . Os resultados indicam ainda que em média

\footnotetext{
${ }^{15} \mathrm{O}$ termo elasticidade nesta abordagem refere-se ao quadro de equilíbrio geral. Classicamente, uma elasticidade captura uma relação entre duas variáveis, tudo o mais constante. Neste caso, é possível observar as relações entre duas variáveis em que todos os demais componentes endógenos do sistema econômico se ajustam. A informação fornecida é útil, pois indica que a relação entre atividade econômica e emprego não deve ser tomada como estática.
} 
a variação de pessoal empregado para a ocupação de engenheiros é maior do que a expansão do PIB e, principalmente, mais expressiva se comparado às demais ocupações $(1,6$ contra 1,3 e 1,2). A tabela não apresenta o ano de 2009, pois parece que este cálculo não é apropriado: a elasticidade de engenheiros seria próxima a 40 nesse ano. Os resultados sugerem que uma associação simples entre PIB e demanda por trabalho especializado é inadequada em anos atípicos, e que se deve observar com cuidado a composição do crescimento do PIB nessa relação com o uso de trabalho.

Tabela 6 - Elasticidades implícitas do emprego por ocupação em relação ao PIB

\begin{tabular}{lccccc}
\hline Variáveis & 2006 & 2007 & 2008 & 2010 & Média \\
\hline Emprego Técnicos & 1,70 & 1,20 & 1,10 & 1,10 & 1,30 \\
Emprego Engenheiros & 2,10 & 1,50 & 1,20 & 1,50 & 1,60 \\
Emprego Diretores & 1,50 & 1,10 & 1,00 & 0,90 & 1,10 \\
Emprego Gerentes & 1,60 & 1,20 & 1,00 & 1,20 & 1,30 \\
Emprego Outros & 1,60 & 1,20 & 1,30 & 0,90 & 1,20 \\
Emprego Total & 1,60 & 1,20 & 1,30 & 0,90 & 1,30 \\
\hline
\end{tabular}

Fonte: Resultados das simulações.

Nota: as elasticidades são obtidas pela razão: variação (\%) do emprego/ variação ( \%) do PIB.

Os resultados setoriais do cenário para a indústria, exibidos na Tabela 7, ajudam o entendimento do impacto observado no uso de trabalho especializado. Foram selecionados os 10 setores com maior impacto do cenário e os 10 setores com menor impacto. Os setores relacionados mais diretamente ao investimento da economia são os que mais flutuam ao longo dos anos (Máquinas, Construção e Cimento). 
Tabela 7 -Impactos sobre o nível de produção setorial da indústria entre 2006 e 2010 (variação \% real ao ano)

\begin{tabular}{lcccccc}
\hline Atividades industriais & 2006 & 2007 & 2008 & 2009 & 2010 & Média \\
\hline \multicolumn{1}{c}{ Maiores impactos } & & & & \\
\hline Construção & 9,30 & 12,70 & 15,30 & $-15,00$ & 19,20 & 8,30 \\
Escritório e Informática & 9,90 & 12,10 & 13,30 & $-14,50$ & 18,70 & 7,90 \\
Cimento & 8,00 & 10,20 & 11,80 & $-11,00$ & 16,00 & 7,00 \\
\hline Petróleo e gás & 7,30 & 5,80 & 3,20 & 2,20 & 7,70 & 5,30 \\
\hline Produtos farmacêuticos & 4,50 & 6,20 & 4,30 & 3,40 & 7,80 & 5,30 \\
\hline Minério de ferro & 2,90 & 11,00 & 4,90 & $-3,80$ & 11,10 & 5,20 \\
\hline Material eletrônico e comunicações & 6,60 & 8,40 & 9,80 & $-14,80$ & 15,90 & 5,20 \\
\hline Indústrias diversas & 4,80 & 6,80 & 6,10 & $-1,90$ & 9,90 & 5,10 \\
\hline Outros minerais não-metálicos & 6,70 & 7,50 & 8,00 & $-11,00$ & 14,50 & 5,10 \\
\hline Automóveis, camionetas e utilitários & 2,20 & 17,70 & 9,50 & $-15,20$ & 10,70 & 5,00 \\
\hline & Menores impactos & & & & \\
\hline Equipamentos e materiais elétricos & 2,60 & 4,80 & 4,10 & $-9,50$ & 10,30 & 2,40 \\
\hline Couro e calçados & 4,80 & 1,80 & $-2,30$ & $-1,80$ & 7,50 & 2,00 \\
\hline Fabricação de aço e derivados & 0,80 & 6,00 & 3,50 & $-11,80$ & 10,40 & 1,80 \\
\hline Fabricação de resinas e elastômeros & 0,50 & 3,40 & $-1,60$ & $-0,70$ & 6,80 & 1,70 \\
\hline Artigos de borracha e plástico & 1,90 & 4,10 & $-0,80$ & $-3,90$ & 7,30 & 1,70 \\
\hline Químicos diversos & 1,90 & 2,40 & $-2,70$ & $-2,90$ & 7,30 & 1,20 \\
\hline Máquinas e equipamentos & 0,80 & 3,00 & $-1,30$ & $-8,20$ & 9,60 & 0,80 \\
\hline Têxteis & $-1,20$ & 1,10 & $-4,50$ & 4,30 & 3,30 & 0,60 \\
\hline Metalurgia de metais não ferrosos & $-0,70$ & 4,60 & 0,20 & $-17,20$ & 9,60 & $-0,70$ \\
\hline Produtos de madeira (exceto móveis) & 0,20 & 4,10 & $-5,50$ & $-14,80$ & 12,40 & $-0,70$ \\
\hline & & & & & & \\
\hline
\end{tabular}

Fonte: Resultados das simulações.

Nota-se também que os setores intensivos no uso de técnicos têm comportamento favorável ao longo do cenário, como Automóveis, Fabricação de Aço e Farmacêuticos. Alguns setores industriais, menos intensivos em trabalho de técnicos e engenheiros (couro e calçado, borracha e plástico e produtos da madeira) acompanham de perto o comportamento da trajetória do PIB. A exceção ocorre no ano de 2008, período que mostra um grande efeito negativo sobre a atividade de tais setores, o que se explica pelo significativo crescimento das importações (22\%) no mesmo período, aumentando a competição no mercado interno para esses setores industriais. 


\subsection{Simulações de restrição na oferta de trabalho especializado}

As projeções anteriores evidenciaram os desdobramentos econômicos do cenário básico da economia brasileira sobre a demanda de trabalho especializado. Nesse ambiente econômico não houve a suposição da restrição de oferta de trabalho em todas as ocupações. Entretanto, essa hipótese pode ser tratada em um cenário de política, que só difere do cenário básico por considerar choques de valores em alguns instrumentos de política, como a restrição de oferta de trabalho em alguns tipos de ocupações (Técnicos e Engenheiros). A distinção entre o cenário de política e o cenário base pode ser interpretada como os efeitos econômicos dessas restrições de oferta de trabalho. ${ }^{16}$ Esses efeitos econômicos, avaliados tanto em termos macroeconômicos como setoriais, permitem, portanto, evidenciar o papel que a própria restrição de oferta de trabalho ("apagão de engenheiros") teria sobre a trajetória futura de crescimento da economia brasileira. ${ }^{17}$

No cenário de política deste estudo, a oferta de trabalho para engenheiros ou técnicos é tratada como exógena, de forma que o preço desse fator apresenta um desvio endógeno relativamente ao custo dos demais tipos de trabalho. Ou melhor, neste ambiente econômico há uma troca entre a variável de oferta de trabalho e a variável de deslocamento de salário para engenheiros e técnicos. Assim, uma vez exógena a variável de oferta de ambas as ocupações, é possível definir os seus valores de choques. Basicamente, esses valores são iguais, porém separados por ocupação na estratégia de simulação deste estudo. A primeira etapa consiste em simular uma restrição de oferta de Técnicos de 0,5\% a.a. a partir de 2011, resultando em desvio acumulado de $-5,0 \%$ até 2020 . Por sua vez, na segunda etapa de simulação a mesma restrição é imposta, mas sobre a oferta de Engenheiros. Cabe ainda salientar que essa restrição é colocada sobre um cenário de crescimento homogêneo de 4,5\% a.a., de 2011 a 2020. O cenário de 2011-2020 parte do estado da economia em 2010, retratado pela base de dados do modelo atualizada a partir da última simulação (2010) da seção anterior.

\footnotetext{
16 Também chamados de instrumentos de política.

17 Cabe salientar que essa restrição é colocada sobre um cenário de crescimento homogêneo de 4,5\% a.a., de 2011 a 2020. O cenário de 2011-2020 parte do estado da economia em 2010, retratado pela base de dados do modelo atualizada a partir da última simulação (2010) da seção anterior. Cabe ressaltar que a taxa de crescimento considerada é apenas ilustrativa. Como são relevantes para a análise apenas os desvios causados pelas restrições na oferta de trabalho, e o cenário base é homogêneo em todos os setores, o valor desta taxa não é relevante.
} 
Embora esses valores de choque sejam arbitrários no cenário de política, tais instrumentos devem repercutir de forma diferenciada nos indicadores macroeconômicos e no nível de atividade dos setores industriais, uma vez que as simulações realizadas englobam transmissões e intensidades distintas, tanto em virtude das assimetrias na estrutura de custos e demanda de cada atividade industrial, como dos diferentes valores calibrados para os parâmetros estruturais do modelo. Por essas razões, os choques homogêneos podem fornecer respostas distintas e desproporcionais, o que favorece para uma análise comparativa e qualitativa dentro da economia brasileira (e.g., setores mais e menos afetados, deslocamentos intersetoriais mais afetados de capital e trabalho e componentes agregados mais sensíveis).

Um conjunto importante de resultados é o efeito setorial das simulações de restrição de oferta de engenheiros e técnicos. A Tabela 8 expõe os resultados projetados da restrição de oferta de profissionais de engenharia e técnicos sobre o nível de atividade e os custos de produção dos setores industriais. Tanto na simulação de restrição na oferta de engenheiros quanto à restrição de técnicos, como não existe a possibilidade de substituição entre as diversas ocupações, ocorre um aumento no preço da mão de obra, resultando em elevação de custos de trabalho para os setores. Aqueles setores mais intensivos em trabalho e que possuem grande participação de engenheiros e técnicos na remuneração total do trabalho sofreriam restrições e dificuldades de maior intensidade, se avaliadas pelo aumento dos custos desse fator primário e pelo nível de atividade (Tabela 8).

Os impactos da restrição de engenheiros ou técnicos tendem a atuar em duas frentes distintas em relação aos custos de produção. Primeiro, para os setores com elevada participação dessas qualificações na mão de obra empregada, há um aumento dos custos em razão da menor capacidade de substituição como forma de ajuste aos novos preços relativos dos fatores primários, especialmente do fator trabalho. Segundo, a queda na produção dessas atividades representa menores requerimentos de insumos na economia, pressionando para uma queda dos preços em outros mercados, uma vez que as transmissões desses efeitos são sistêmicas. Entretanto, a intensidade dos efeitos sobre os custos de produção dos setores é heterogênea e dependerá da tecnologia de produção, da composição entre os fatores primários e elasticidades de substituição capital/trabalho. 
Tabela 8 - Efeitos da restrição de oferta de trabalho de Engenheiros na indústria (desvio \% acumulado no nível de atividade em 2020)

\begin{tabular}{|c|c|c|c|c|}
\hline \multirow{3}{*}{ Setor } & \multicolumn{4}{|c|}{ Simulação de restrição de: } \\
\hline & \multicolumn{2}{|c|}{ Engenheiros } & \multicolumn{2}{|c|}{ Técnicos } \\
\hline & $\begin{array}{l}\text { Nível de } \\
\text { atividade }\end{array}$ & $\begin{array}{l}\text { Custos de } \\
\text { produção }\end{array}$ & $\begin{array}{l}\text { Nível de } \\
\text { atividade }\end{array}$ & $\begin{array}{l}\text { Custos de } \\
\text { produção }\end{array}$ \\
\hline Agricultura & 0,1 & $-0,4$ & 1,7 & $-4,3$ \\
\hline Pecuária & 0,2 & $-1,3$ & 1,3 & $-6,5$ \\
\hline Petróleo e gás natural & $-1,8$ & 3,2 & $-2,7$ & 5,1 \\
\hline Minério de ferro & $-0,8$ & 1,1 & $-1,2$ & 1,5 \\
\hline Outros da indústria extrativa & $-0,9$ & 0,9 & $-0,9$ & 0,7 \\
\hline Alimentos e Bebidas & 0,2 & $-0,7$ & 1,0 & $-3,8$ \\
\hline Produtos do fumo & 0,2 & $-0,6$ & 0,2 & $-1,2$ \\
\hline Têxteis & 0,2 & $-0,5$ & 0,4 & $-2,4$ \\
\hline Artigos do vestuário e acessórios & 0,2 & $-1,2$ & 0,7 & $-5,1$ \\
\hline Artefatos de couro e calçados & 0,3 & $-1,3$ & 1,8 & $-6,0$ \\
\hline Produtos de madeira - exclusive móveis & 0,0 & $-1,1$ & 2,2 & $-7,0$ \\
\hline Celulose e produtos de papel & $-0,1$ & 0,0 & $-1,2$ & 0,7 \\
\hline Jornais, revistas, discos & $-0,1$ & $-1,2$ & $-1,2$ & $-1,2$ \\
\hline Refino de petróleo e coque & $-0,9$ & 2,8 & $-1,2$ & 2,6 \\
\hline Álcool & $-0,6$ & $-0,4$ & $-0,2$ & $-4,1$ \\
\hline Produtos químicos & $-0,6$ & 1,1 & $-1,0$ & 1,6 \\
\hline Fabricação de resina e elastômeros & $-0,7$ & 1,1 & $-1,9$ & 2,2 \\
\hline Produtos farmacêuticos & 0,0 & $-0,4$ & $-5,3$ & 11,8 \\
\hline Defensivos agrícolas & 0,0 & 0,8 & 0,3 & 2,3 \\
\hline Perfumaria, higiene e limpeza & $-0,1$ & $-0,2$ & $-1,6$ & 0,0 \\
\hline Tintas, vernizes, esmaltes e lacas & $-0,6$ & 0,1 & $-1,8$ & 3,7 \\
\hline Produtos e preparados químicos diversos & $-0,4$ & 0,4 & $-2,1$ & 2,3 \\
\hline Artigos de borracha e plástico & $-0,4$ & 0,0 & $-1,7$ & 1,3 \\
\hline Cimento & $-1,1$ & 0,9 & $-1,6$ & 3,4 \\
\hline Outros produtos de minerais não-metálicos & $-0,6$ & $-0,2$ & $-0,7$ & $-2,5$ \\
\hline Fabricação de aço e derivados & $-0,9$ & 0,9 & $-2,0$ & 2,5 \\
\hline Metalurgia de metais não-ferrosos & $-1,0$ & 0,6 & $-1,8$ & 0,9 \\
\hline Prod. de metal-exclusive máquinas e equipamentos & $-0,8$ & 0,0 & $-1,5$ & 0,1 \\
\hline Máquinas e equip., inclusive manutenção e reparos & $-1,2$ & 0,9 & $-2,6$ & 2,7 \\
\hline Eletrodomésticos & $-0,7$ & 0,7 & $-2,7$ & 2,1 \\
\hline Máquinas para escritório e equipamentos de informática & $-1,0$ & 0,3 & $-1,7$ & 1,4 \\
\hline Máquinas, aparelhos e materiais elétricos & $-1,1$ & 1,4 & $-2,0$ & 1,7 \\
\hline Material eletrônico e equipamentos de comunicações & $-1,1$ & 0,8 & $-2,1$ & 1,9 \\
\hline Aparelhos/instrumentos médico-hospitalar, medida e óptico & $-0,9$ & 0,7 & $-3,3$ & 3,2 \\
\hline Automóveis, camionetas e utilitários & $-0,6$ & 0,4 & $-1,3$ & 0,5 \\
\hline Caminhões e ônibus & $-0,8$ & 0,6 & $-1,8$ & 2,7 \\
\hline Peças e acessórios para veículos automotores & $-0,4$ & 0,6 & $-1,4$ & 2,0 \\
\hline Outros equipamentos de transporte & $-2,6$ & 3,0 & $-2,6$ & 2,6 \\
\hline Móveis e produtos das indústrias diversas & 0,0 & $-1,0$ & 0,7 & $-4,3$ \\
\hline Eletricidade e gás, água, esgoto e limpeza urbana & $-1,5$ & 2,5 & $-2,9$ & 2,8 \\
\hline Serviços (agregado) & $-0,2$ & $-0,9$ & $-0,7$ & $-3,1$ \\
\hline
\end{tabular}

Fonte: Resultados das simulações. 
É possível observar que 30 das 40 atividades industriais sofreriam uma retração na produção com a restrição de engenheiros. Os setores mais afetados nessa simulação seriam Outros Equipamentos de Transporte, Petróleo e Gás, Máquinas e Equipamentos de Manutenção e Refino de Petróleo. Conforme a Tabela 2, estes setores exibem uma elevada participação de engenheiros na composição de seus custos de trabalho (no setor de Refino chega a 30\%). Vale notar que o setor de Outros Equipamentos de Transporte é um dos que mais apresentaram empresas que reportaram dificuldades em encontrar trabalho especializado, segundo pesquisa recente da Confederação Nacional das Indústrias (CNI, 2011).

Alguns setores, por outro lado, foram pouco afetados ou apresentaram elevação do nível de atividade nas simulações. Este efeito se explica ou por serem setores mais intensivos em capital e/ou apresentarem relativamente baixa composição destes tipos de trabalho em sua mão de obra total. Setores típicos de bens de consumo (Têxteis, Calcados e Vestuário) e Alimentos, neste caso, são pouco afetados pela restrição de oferta de engenheiros e técnicos, apresentando inclusive elevação do nível de atividade. Nestes casos, os setores são pouco dependentes desse tipo de mão de obra e, portanto, tem maior capacidade de substituição capital/trabalho como forma de ajuste aos novos preços relativos dos fatores primários.

Fabricação de Produtos Farmacêuticos, por sua vez, exibe padrões diferenciados nas simulações. Na restrição de engenheiros, o setor não é afetado dado a menor composição deste tipo de trabalho nos custos de produção do setor. Contudo, é o setor mais negativamente afetado quando a restrição sobre oferta de técnicos é imposta, influenciado pela grande participação destes profissionais no setor. Em seguida, aparecem os setores de Eletricidade e gás, Máquinas e Equipamentos, Petróleo e Gás, Aparelhos médicos hospitalares, Eletrodomésticos e Outros equipamentos de transporte. Destacamse também os impactos sobre setores de insumos intermediários (Refino, Químicos e Resinas) e exportadores, como Minério de Ferro.

Os resultados macroeconômicos das simulações de restrição de oferta de trabalho são ilustrados na Figura 2. Os gráficos apresentam o impacto anual sobre o Produto Interno Bruto (PIB), investimento, consumo das famílias, exportações e emprego, em termos de desvio 
acumulado relativo ao cenário 2011-2020. Observa-se que essa restrição leva a uma contração dos principais indicadores macroeconômicos ao longo do tempo, com quedas do PIB e do emprego, entre 0,2\% a 0,7\% em 2020 (Tabela 8). Ou seja, uma restrição de 5\% no crescimento da oferta de engenheiros, por exemplo, implicaria uma queda de $-0,3 \%$ do PIB e $-0,2 \%$ do emprego, relativamente a um cenário no qual essa restrição não ocorresse.

O investimento $(-1,2 \%)$ é o componente mais afetado pela restrição de oferta de engenheiros na economia. A contração do investimento agregado reflete o fato de que setores trabalho-intensivos registram quedas importantes no investimento. Isso ocorre devido à capacidade de substituição entre capital e trabalho e à intensidade no uso desses fatores, diferenciadas por setor. A restrição da mão de obra de engenheiros encarece esse fator específico e, como as atividades que utilizam esta ocupação em maior proporção são capital-intensivas, ocorre um incentivo à substituição entre capital e trabalho. A maior demanda por capital pressiona seu preço, isto é, induz um aumento de sua rentabilidade, o que incentiva os investimentos e a acumulação de capital dessas atividades (e.g., Refino de Petróleo, Automóveis e utilitários, Outros Equipamentos de transporte, Petróleo e gás). ${ }^{18}$ Por outro lado, nos setores trabalho-intensivos, em que a ocupação de engenheiros detém menor participação na força de trabalho total, a substituição ocorre na direção da absorção da mão de obra liberada nos setores supracitados, havendo substituição entre capital e traba1ho, de modo que a rentabilidade do capital e, consequentemente, os investimentos, sofrem quedas significativas (e.g., Artigos do vestuário, Couro e calçado, Produtos da madeira, Saúde mercantil).

As exportações, por sua vez, apresentam um comportamento peculiar, com um ligeiro aumento nos primeiros anos e queda progressiva até 2020. Esta trajetória é explicada pelo comportamento setorial bastante heterogêneo nas simulações. No modelo, as exportações setoriais respondem a curvas de demanda negativamente associadas aos custos domésticos de produção, ${ }^{19}$ mostrados na Tabela 8. Assim, verifica-se um aumento das exportações principalmente de produtos

\footnotetext{
${ }^{18}$ A taxa de retorno é definida pela diferença entre o preço (rentabilidade) do capital e o preço do investimento. Assim, o investimento em determinado setor se eleva enquanto o diferencial entre esses dois preços é positivo. Contudo, conforme o investimento aumenta e o estoque de capital se acumula, a rentabilidade desse fator tende a cair, reduzindo também o preço do investimento.

${ }^{19}$ Hipótese de país pequeno no comércio internacional.
} 
agropecuários e da indústria leve (alimentos e bebidas, artigos têxteis e de vestuário, calçados), que acabam por repercutir em aumento das exportações agregadas nos primeiros anos. Contudo, a medida que a restrição de engenheiros se torna mais custosa para os demais setores ao longo dos anos, o aumento das exportações daqueles produtos já não consegue compensar a diminuição das exportações da indústria extrativa e da indústria intermediária e pesada.

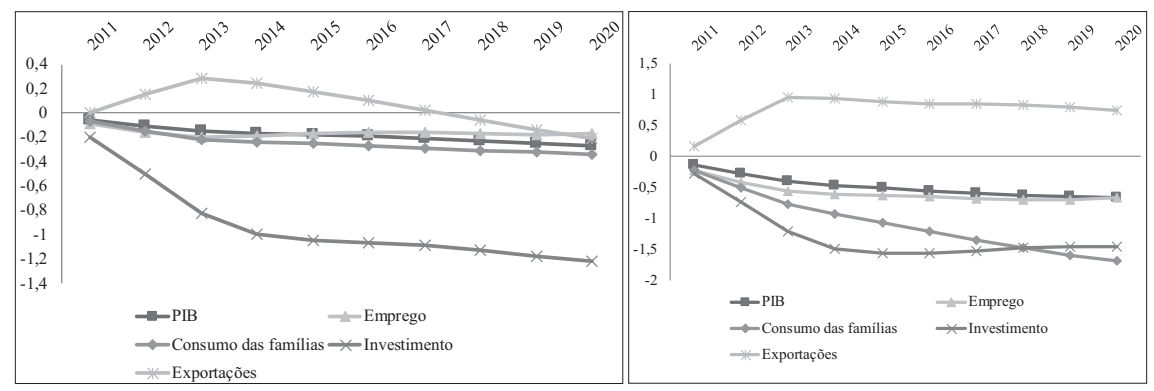

(a) Simulação de restrição de Engenheiros

(b) Simulação de restrição de Técnicos

Figura 2 - Efeitos da restrição de oferta de Engenheiros e Técnicos sobre os principais agregados macroeconômicos (desvio \% acumulado em relação ao cenário de referência)

Fonte: Resultados das simulações.

Na simulação de restrição na oferta de técnicos, por seu turno, o PIB brasileiro sofreria uma retração de $-0,7 \%$ em 2020 , superior ao efeito da restrição de engenheiros. Os resultados projetados indicam que a queda mais proeminente do PIB se dá pela redução mais intensa do investimento $(-1,4 \%)$ e do consumo das famílias $(-1,7 \%)$ no acumulado em 2020, explicado pela importância e preponderância desta categoria para a maioria dos setores. O recuo no emprego total, por exemplo, chega a $-0,7 \%$, com impacto direto sobre o consumo das famílias.

Já o comportamento das exportações se assemelha à simulação de restrição de engenheiros, de leve acréscimo nos primeiros anos. Contudo, a partir de 2013, há apenas uma ligeira queda se estabilizando em torno de $0,7 \%$ de aumento acumulado até 2020, principalmente em decorrência da redução dos preços internos dado pelo recuo no nível de atividade da economia. A Tabela 9 sumariza os impactos das restrições de oferta de engenheiros e técnicos na eco- 
nomia. A restrição de técnicos repercute de forma mais forte sobre o PIB e o consumo das famílias, comparativamente a simulação de restrição a engenheiros. Para o investimento, o efeito das duas restrições é semelhante, resultado interessante quando se tem em mente que a ocupação de técnicos detém participação mais elevada na força de trabalho total. Isso ocorre pelo padrão dos efeitos sobre o investimento setorial. A restrição de engenheiros promove um "efeito de arrasto" negativo mais amplo, atingindo grande parte dos setores da indústria intermediária (e.g., Minério de ferro, Transporte, armazenagem e correios, Químicos diversos). Já na restrição de técnicos, embora sejam verificados impactos negativos de maior magnitude no investimento das atividades trabalho-intensivas, o "efeito de arrasto" negativo é de menor proporção em relação ao investimento. Em relação ao empego, apesar de o efeito ser semelhante, a repercussão indireta da restrição de um tipo sobre outro é maior para técnicos. O choque de $-5 \%$ em técnicos diminui o uso de engenheiros em $-6,6 \%$, mais que proporcionalmente. Já o choque de $-5 \%$ em engenheiros reduz o uso de técnicos em -1,2\%.

Tabela 9 - Efeitos da restrição de oferta de trabalho especializado (desvio \% acumulado em 2020)

\begin{tabular}{lccc}
\hline \multirow{2}{*}{\multicolumn{1}{c}{ Variáveis }} & \multicolumn{2}{c}{ Restricão da oferta de trabalho } \\
\cline { 2 - 3 } Congenheiros & $-0,3$ & Técnicos \\
\hline PIB & $-0,3$ & $-0,7$ \\
Investimento & $-1,2$ & $-1,7$ \\
Exportações & $-0,2$ & $-1,4$ \\
Emprego Total & $-0,2$ & 0,7 \\
Emprego de Diretores & $-0,2$ & $-0,7$ \\
Emprego de Gerentes & $-0,1$ & $-1,9$ \\
Emprego de Técnicos & $-1,2$ & $-1,2$ \\
Emprego de Engenheiros & $-5,0^{*}$ & & $-5,0^{*}$ \\
Emprego de Outros trabalhadores & $-0,1$ & $-6,6$ \\
\hline
\end{tabular}

Fonte: Resultados das simulações.

* Choques

Esse "efeito de arrasto" de uma ocupação sobre outra ocorre tanto pela especificação do modelo (inexiste possibilidade de substituição entre os tipos de mão de obra, e um setor negativamente afetado pela restrição de oferta acaba diminuindo o uso de todos os tipos de trabalho) como pelos efeitos desencadeados nas cadeias produtivas. Além disso, como a restrição de técnicos afeta diretamente vários 
setores, inclusive os de serviços, e estes têm parcela significativa na remuneração de trabalho e como insumo de setores industriais, a repercussão no uso de engenheiros acaba sendo maior.

\section{Considerações finais}

A conjuntura econômica favorável para o Brasil de 2005 a 2011, mesmo com a crise financeira de 2008-09, gerou preocupações em diversos fóruns de discussão sobre restrições estruturais ao crescimento da economia, como a escassez de trabalho especializado, especialmente de técnicos e engenheiros. Essa escassez pode ser um entrave para uma trajetória de crescimento econômico mais acelerada no Brasil. Temores de um possível "apagão" de pessoal técnico-científico, em especial de engenheiros, têm sido levantados por especialistas, autoridades e de forma bastante generalizada pela imprensa. Nesse contexto, questiona-se se existem potenciais riscos de escassez de trabalho especializado na economia brasileira e quais seriam as implicações desse gargalo, especialmente na indústria.

Utilizamos um modelo de equilíbrio geral computável na análise da dinâmica recente e dos efeitos da escassez de trabalho especializado na economia brasileira. Essa metodologia tem a vantagem de levar em conta a utilização de mão de obra especializada em todos os setores produtivos, e também as cadeias produtivas que necessariamente repercutem o efeito de uma restrição de oferta de trabalho para todo o sistema econômico. No modelo e nas simulações deste artigo, são utilizadas cinco ocupações do fator trabalho: engenheiros, técnicos, gerentes, diretores e demais ocupações. Foram realizados três conjuntos de simulações: i) a primeira é do cenário macroeconômico observado de 2006 a 2010; ii) a segunda, um cenário de restrição na oferta de trabalho de Engenheiros a partir de 2011; e iii) a terceira, a mesma restrição de oferta de trabalho, mas relativa a Técnicos.

Os resultados das simulações do cenário 2006-2010 apontaram para o crescimento acelerado no uso de engenheiros e técnicos na maioria dos anos, principalmente devido à expansão dos setores mais influenciados pela dinâmica do investimento. Os resultados apontam que em períodos de maior crescimento econômico (como em 2010, $7,1 \%$ ), existiria uma demanda acima da média por engenheiros e 
técnicos (respectivamente 11,6\% e 8,4\%). As elasticidades médias implícitas das ocupações em relação ao PIB sugerem que a resposta no uso de trabalho especializado, notadamente engenheiros (média de 1,6$)$ não é superior a dois, como apontado em alguns estudos. Entretanto, em período de desaceleração significativa, como em 2009, a resposta (negativa) no uso de técnicos e engenheiros pode ser muito mais elástica, pois está associada ao comportamento do investimento. $\mathrm{O}$ inverso se espera em anos de recuperação econômica, como 2010.

A escassez de engenheiros e de técnicos gera efeitos adversos sobre os principais indicadores macroeconômicos e setoriais, principalmente considerando a restrição sobre a oferta de engenheiros, já que esta ocupação representa menos de $0,5 \%$ da força de trabalho e traz impactos negativos importantes. Vale ressaltar que esta ocupação é bastante relevante em setores de bens de capital e insumos intermediários, o que dissemina o efeito dessa restrição por toda a economia. Um exemplo é o elevado impacto no investimento. Nas simulações, os setores mais afetados em termos de produção são aqueles ligados a bens de capital (Máquinas e Equipamentos de Transportes), Extração Mineral (como Petróleo e Gás), e insumos intermediários (produtos do refino e químicos), resultados similares aos encontrados por Maciente e Araújo (2011). Este é um ponto preocupante dado que tais setores permeiam diversas cadeias produtivas industriais, e são importantes na estrutura de investimento da economia. Em virtude da interdependência tecnológica das ocupações na produção, a restrição de oferta de um tipo de trabalho especializado pode levar à redução relativa das demais ocupações ("efeito de arrasto"). Comparativamente, observou-se que os efeitos negativos da restrição de técnicos sobre a demanda das demais ocupações são mais intensos e diretos que os efeitos negativos da restrição de engenheiros, principalmente porque a ocupação de técnicos tem participação mais significativa na força de trabalho.

Este trabalho pretende contribuir para a discussão de escassez de mão de obra no Brasil e seus impactos sobre o crescimento econômico. Os resultados chamam a atenção para a necessidade de análises setoriais integradas no tocante à discussão de escassez de pessoal especializado, e para a composição do ciclo econômico que influenciam essa demanda. A oscilação no uso de trabalho especializado pode ser um problema importante de coordenação de políticas públicas: 
num período de crise econômica e redução drástica do investimento (2008-09) ocorre queda significativa no uso de trabalho especializado, que depois se recupera fortemente nos anos seguintes, com a recuperação do investimento (como em 2010). Assim, se houver dificuldade na recontratação da mão de obra dispensada, a própria recuperação da crise 2008-09 no longo prazo estaria ameaçada. O mesmo pode ser pensado para o cenário mais recente (2011-2014) de baixo crescimento pelo qual passou a economia brasileira. O arrefecimento da procura por trabalho em geral tenderia a amenizar o problema da escassez de mão de obra especializada, mas a recuperação econômica poderia estar comprometida caso a economia se defronte com uma restrição na oferta desses profissionais.

Como ressaltado por outros estudos, uma importante característica do mercado de trabalho de engenheiros e afins refere-se ao fato de uma considerável fração desses profissionais formados não exercerem a profissão. Os resultados encontrados incorporam esse fator na medida em que as informações utilizadas quanto ao número de engenheiros e outros trabalhadores consideram apenas aqueles que estão exercendo suas atividades formalmente registrados como engenheiros. Desta forma, se a proporção de engenheiros formada que exerce a profissão se mantem relativamente constante ao longo do tempo, esse fator não influencia os resultados obtidos. Por outro lado, é possível conjecturar que em cenários de escassez de mão de obra e elevação dos salários, mais profissionais formados em engenharia que atuam em outras áreas podem decidir ofertar trabalho como engenheiros, o que reduziria a pressão dos efeitos do aumento da demanda. No entanto, com os dados e no modelo utilizado não é possível incorporar esse comportamento.

Outra questão bastante discutida refere-se às deficiências de qualidade na educação básica, sobretudo quanto à baixa proficiência em matemática e ciências, uma vez que as mesmas impõem obstáculos importantes ao sucesso desses profissionais. Nesse sentido, faz-se importante pensar em políticas de curto prazo que procurem melhorar a atratividade dessa mão de obra para ocupações típicas da área, no intuito de atrair aqueles que atuam em outras ocupações, além de novos ingressantes, para os cursos de engenharia. A discussão dos canais que podem ampliar e melhorar a formação desses profissionais no Brasil configura uma importante agenda de pesquisa. 


\section{Referências}

ARAÚJO, B. C.; CAVALCANTE, L. R.; ALVES, P. Variáveis proxy para os gastos empresariais em inovação com base no pessoal ocupado técnico-científico disponível na Relação Anual de Informações Sociais (RAIS). Radar, Brasília: Ipea, n. 5, dez. 2009.

BARROS, M. A. Relatório sobre o trabalho de identificação de lacunas de recursos de engenharia de projeto para a área de TM. Rio de Janeiro: Petrobras, 2004.

BITENCOURT, M. B. \& TEIXEIRA, E. C. Impactos dos encargos sociais na economia brasileira. Nova Economia, 18 (1), n. 5, p. 3-86, jan./abr. 2008.

BOETERS, S. Optimal tax progressivity in unionised labor markets: simulation results for Germany. ZEW Discussion Paper 10e035. ZEW, Mannheim, 2010.

BOETERS, S.; SAVARD, L. The labor Market in Computable General Equilibrium Models. In: DIXON, P. B.; JORGESON, D. W. (Eds). Handbook of Computable General Equilibrium Modeling. Amsterdam: Elsevier, vol. 1, ch. 26, pag. 1645-1718, 2013.

BOHRINGER, C., BOETERS, S., FEIL, M. Taxation and unemployment: an applied general equilibrium approach for Germany. Econ. Model, v. 22, 81-108, 2005.

BOURGUIGNON, F., SAVARD, L. A CGE integrated multi-household model with segmented labor markets and unemployment. In: Bourguignon, F., Pereira da Silva, L.A., Bussolo, M. (Eds), The Impact of Macroeconomic Policies on Poverty and Income Distribution: Macro-Micro Evaluation Techniques and Tools. Palgrave-Macmillan, Basingstoke, pp. 177-212, 2008.

CONSELHO NACIONAL DA INDÚSTRIA (CNI). Falta de trabalhador qualificado na indústria. Sondagem especial, ano 9, n. 2, 2011. Disponível em: http://www.cni.org.br. Acesso em: dezembro de 2011.

CURY, S., LEME, M. C. S. Redução da desigualdade e programas de transferência de renda: uma análise de equilíbrio geral. In: Paes de Barros, R.; Foguel, M. N.; Ulyssea, G. (Eds). Desigualdade de Renda no Brasil: uma análise da queda recente, v. II, cap. 21, 2007.

DE MELO, J., TARR, D., 1992. A General Equilibrium Analysis of US Foreign Trade Policy, MIT Press, Cambridge, MA.

DIXON, P.B.; JOHNSON, M.; RIMMER, M.T. Economy-wide effects of reducing illegal immigrants in US employment. Contemp. Econ. Policy, v. 29, p. 14-30, 2011.

DIXON, P. B.; PARMENTER B. R.; SUTTON, J. M.; VINCENT D. P. ORANI: A Multi Sectoral Model of the Australian Economy. Amsterdam: North-Holland, 1982. 372 p.

DIXON, P.B.; RIMMER, M. Dynamic General Equilibrium Modelling for Forecasting and Policy: a practical guide and documentation of MONASH. Amsterdam: Elsevier, 2002. 338p.

DOMINGUES, E. P. Dimensão regional e setorial da integração brasileira na Área de Livre Comércio das Américas. São Paulo: USP, 2002. 222 p. Tese (Doutorado em Economia) - Universidade de São Paulo, São Paulo, 2002.

DOMINGUES, E. P.; MAGALHÃES, A. S.; BETARELLI JUNIOR, A. A.; CARVALHO, T. S.; SANTIAGO, F. S. The World Financial Crisis in Brazil: Industry and Regional Economic Impacts. Journal of International Business and Economics, v. 2, p. 57-94, 2014.

FERREIRA FILHO, J.B.S.; HORRIDGE, M. Regional Inequality, Poverty and Economic Integration in Brazil. Revista Brasileira de Economia, v. 60, n. 4, p. 363-387, out./dez. 2006.

FOCHEZATTO, A., SOUZA, N. J. Estabilização e reformas estruturais no Brasil após o Plano Real: uma análise de equilíbrio geral computável. Pesquisa e Planejamento Econômico, v. 30, n. 3, p. 395-426. dez. 2000.

FOCHEZATTO, A. Modelos de equilíbrio geral aplicados na análise de políticas fiscais: Uma revisão da literatura. Análise, Porto Alegre, v. 16, n. 1, p. 113-136, jan./jul. 2005. 
FRASER, I., WASCHIK, R.G. The double dividend hypothesis in a CGE model: specific factors and variable labor supply. Discussion Paper 10/01. University of Kent School of Economics, Canterbury, 2010.

FREEMAN, R. B. Is a great labor shortage coming? Replacement demand in the global economy. In: HOLZER, H. J.; NIGHTINGALE, D. S. (Eds.). Reshaping the American workforce in a changing economy. Washington-DC: The Urban Institute, 2007.

HADDAD, E. A.; DOMINGUES, E. P. EFES: Um modelo aplicado de equilíbrio geral para a economia brasileira: projeções setoriais para 1999-2004. Estudos Econômicos. v.31, n.1, p. 89-125, jan./ mar. 2001.

HADDAD, E. A. Retornos crescentes, custos de transporte e crescimento regional. São Paulo: USP, 2004. 203 p. (Tese de Livre Docência) - EAE/FEA/Universidade de São Paulo, São Paulo, 2004.

HARRISON, W.J., PEARSON, K.R. Gempack Document no.GPD-1.Centre of Policy Studies and Impact Project Monash University, Melbourne, Australia.2002.

HASEGAWA, M. M. Políticas públicas na economia brasileira: uma aplicação do modelo MIBRA, um modelo inter-regional aplicado de equilíbrio geral. 2003. Tese (Doutorado em Economia) - ESALQ/USP, Piracicaba/SP, 2003.

HÉRAULT, N. Trade liberalization, poverty and inequality in South Africa: a computable general equilibrium-microsimulation analysis. Econ. Rec., v. 83, p. 317-328, 2007.

HORRIDGE, M. ORANI-G: A Generic Single-Country Computable General Equilibrium Model. Centre of Policy Studies and Impact Project, Monash University, Australia. 2006.

INSTITUTO BRASILEIRO DE GEOGRAFIA E ESTATÍSTICA (IBGE). Pesquisa de Orçamento das Famílias (POF 2003-2004). IBGE, 2004. http://www.ibge.gov.br/home/estatistica/populacao/ pof/2002_2003. Accessed 17 April 2011.

INSTITUTO BRASILEIRO DE GEOGRAFIA E ESTATÍSTICA(IBGE). Sistema de Contas Nacionais. 2004. Disponível em: http://www.ibge.gov.br/home/estatistica/ economia/contasnacionais/2008/ default.shtm. Acesso em: agosto de 2011.

INSTITUTO NACIONAL DE ESTUDOS E PESQUISAS EDUCACIONAIS ANÍSIO TEIXEIRA (INEP). Censos da Educação Superior de 2001 a 2008. Brasília: INEP, 2001-2008. Disponível em: $<$ http://www.inep.gov.br $>$. Acesso em: 31 jan. 2011.

MACIENTE, A. N.; ARAÚJO, T. C. A demanda por engenheiros e profissionais afins no mercado de trabalho formal. Radar, Brasília: Ipea, n. 12, fev. 2011.

MINISTÉRIO DO TRABALHO E EMPREGO (MTE). Relação Anual Informações Sociais (Rais) de 1986 a 2009. Brasília: MTE, 1986-2009.

NASCIMENTO, P. A. M. M.; MACIENTE, A. N.; GUSSO, D. A; ARAÚJO.; T. C.; SILVA, A. P. T. Escassez de engenheiros: realmente um risco? Radar, Brasília: Ipea, n. 6, fev. 2010.

PEREIRA, R. H. M.; ARAÚJO, T. C. Oferta de engenheiros e profissionais afins no Brasil: resultados de projeções iniciais para 2020. Radar, Brasília: Ipea, n. 12, fev. 2011.

PETER, W. W. HORRIDGE, M.; MEGUER, G.A. NAVQUI, F.; PARMENTER, B. R. The theoretical structure of MONASH-MRF. Cayton: Center of Policy Studies, 1996. 121 p. (Preliminary working paper, OP-85). Disponível em: https://www.vu.edu.au/centre-of-policy-studies-cops. Acesso em: julho de 2010.

POMPERMAYER, F. M.; NASCIMENTO, P. A. M. M; MACIENTE, A. N.; GUSSO, D. A.; PEREIRA, R. H. M. Potenciais gargalos e prováveis caminhos de ajustes no mundo do trabalho no Brasil nos próximos anos. Radar, Brasília: Ipea, n. 12, fev. 2011.

SAHIN, A.; SONG, J.; TOPA, GIORGIO; VIOLANTE, G. Measuring mismatch in the U.S. labor market. Federal Reserve Bank of New York, working paper, revised October, 2011. 
SLAUGHTER, M.E., SWAGEL, P. Does globalization lower wages and export jobs? Washington: Economic Issues IMF, n.11, p.1-19, 1997. Disponível em http://www.imf.org/external/pubs/ft/ issues11/issue11.pdf. Acesso em dezembro de 2011.

SOUZA, K. B.; DOMINGUES, E. P. Mudanças no mercado de serviços domésticos: uma análise da evolução dos salários no período 2006-2011. Economia Aplicada, v. 18, p. 319-346, 2014.

SOUZA, K. B. Impactos econômicos da participação da mulher no mercado de trabalho brasileiro: uma análise de equilibrio geral. Belo Horizonte: UFMG, 2015. Tese (Doutorado em Economia) - Universidade Federal de Minas Gerais, Belo Horizonte, 2015. (mimeo).

SOUZA, K. B.; CARDOSO, D. F.; DOMINGUES, E. P. Medidas recentes de desoneração tributária no Brasil: uma análise de equilíbrio geral computável. Revista Brasileira de Economia, v. 70, n. 1, 2016.

TEITELBAUM, M. S. Do we need more scientists? In: KELLY, T. K. et al. (Eds.). Anais da conferência: "The US scientific and technical workforce: improving data for decision making". Santa Monica-CA: Rand Corporation, jun. 2004.

VILLELA, P. R. C. Escassez de mão de obra. In: Software e serviços de TI:a Indústria brasileira em perspectiva. Campinas: Observatório Softex, cap. 10, 2009.

\section{Anexo I - Ajuste intertemporal no mercado de trabalho}

O mercado de trabalho apresenta um elemento de ajuste intertemporal dos salários reais, envolvendo basicamente duas outras variáveis: o emprego atual e emprego tendencial. Assume-se que a demanda por trabalho determina a quantidade de trabalhadores utilizados na produção e que os salários reais são rígidos no curto prazo, mas flexíveis no longo prazo. Esquematicamente, o equilíbrio a cada ano para cada um dos tipos de trabalhadores pode ser representado pela Figura 3.

Assumindo que a economia esteja incialmente em estado estacionário, um aumento da produção nesta economia, tudo o mais constante, desloca a curva de demanda por trabalho para direita (por exemplo, de $D$ para $D^{\prime}$ ). Como os salários são rígidos no curto prazo, ocorre um aumento do emprego em relação ao tendencial. Com o passar do tempo, os preços vão se ajustando (aumentando), assim como os salários reais. Isto provoca um deslocamento da curva de oferta de trabalho para a esquerda até que o emprego alcance novamente o nível tendencial. 


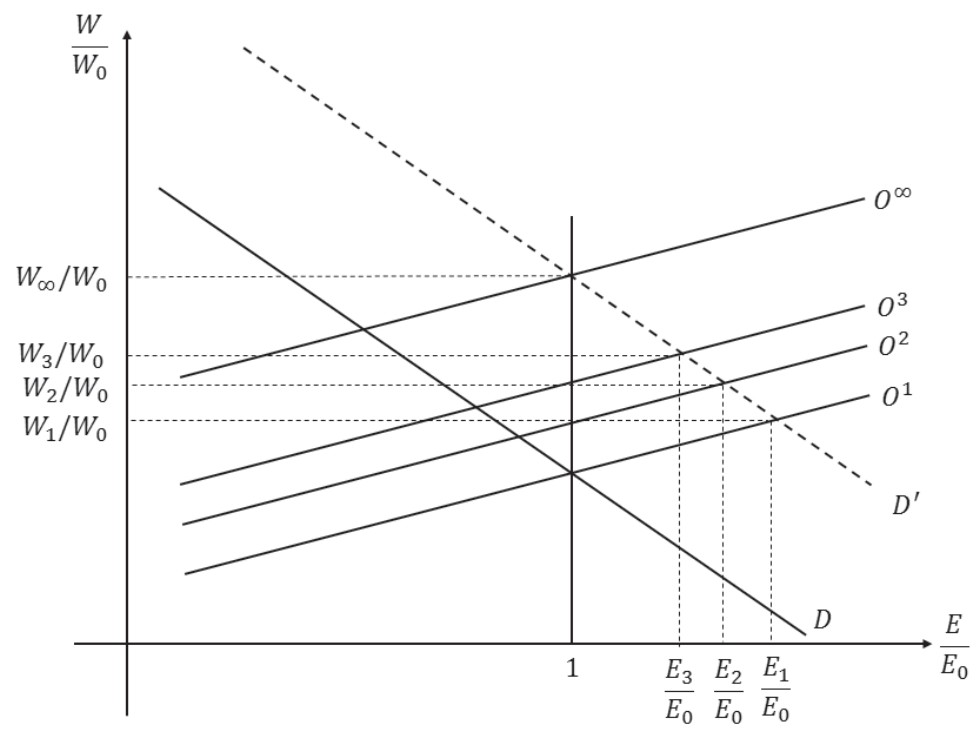

Figura 3 - Ajustamento dos salários reais

Fonte: Dixon e Rimmer (2002, pp. 207).

Formalmente, assume-se que quando o nível de emprego em $t+1$ excede em $E \%$ o crescimento tendencial, o salário real aumenta em $\gamma E \%$. Logo, visto que existe uma relação negativa entre emprego e salário real no mercado de trabalho, o nível de emprego em períodos posteriores se ajustará até convergir para o nível tendencial. Portanto, o equilíbrio no mercado de trabalho é dado por:

$$
\frac{\Delta w}{\Delta 0}=\gamma\left(\frac{L}{T}+\frac{\Delta L}{T}\right)
$$

em que $L$ é o nível de emprego atual; $T$ representa ao nível de emprego tendencial; e $w$ é o salário real. Logo, como o emprego é negativamente relacionado aos salários reais, enquanto o nível de emprego estiver acima do tendencial, o salário real aumenta, da mesma forma, quando o emprego está abaixo do nível tendencial o salário real diminui, incentivando posteriores aumentos na demanda por trabalho e assim equilibrando o mercado de trabalho. 
Esse comportamento do mercado de trabalho é consistente com a existência de uma taxa de desemprego NAIRU (non-accelerating inflation rate of unemployment) exógena ou fracamente dependente dos salários reais (Dixon e Rimmer, 2002). Vale ressaltar que não foram consideradas possíveis mudanças na participação da força de trabalho, ou na taxa de desemprego, o choque imposto equivale a uma alteração exógena na oferta de trabalho, que afeta os salários reais via o deslocamento da curva de oferta e, por conseguinte, altera o equilíbrio do mercado de trabalho.

\section{Anexo II - Análise de sensibilidade}

$\mathrm{Na}$ implementação do modelo, uma série de parâmetros comportamentais são utilizados. Algumas são baseadas em estimativas econométricas e outros são atribuídos valores com base em conhecimentos econômicos e suposições. Pode não ser válida a alegação de que todos os parâmetros utilizados no modelo refletem a realidade. Essa dependência de estimativas para determinar os valores de elasticidade no processo de calibração do modelo é um tópico muito questionado, principalmente por aqueles que não utilizam a metodologia.

Assim, a análise de sensibilidade dos parâmetros se tornou uma questão primordial quando da utilização de modelos EGC. A análise de sensibilidade sistemática empregada neste trabalho segue a metodologia de quadratura gaussiana proposta por DeVuyst e Preckel (1997). Nessa abordagem, o modelo EGC é tratado como um problema de integração numérica no qual a solução do modelo (resultado das variáveis endógenas) pode ser obtida simultaneamente, além de seus dois primeiros momentos (média e variância), dada uma distribuição das variáveis exógenas (parâmetros ou choques). Assim, as estimativas de média, desvio padrão e intervalos de confiança para os resultados do modelo podem ser obtidos. Estas informações representam dados qualitativos a respeito da sensibilidade dos resultados do modelo a parâmetros específicos, e podem sugerir os elementos para onde a atenção do pesquisador deve estar focada. Dadas as considerações acima, a análise de sensibilidade sistemática consistiu em testar a robustez das elasticidades do modelo, que estão apresentadas no Quadro 2. 
Quadro 2 - Elasticidades e parâmetros do modelo

\begin{tabular}{lccc}
\hline Parâmetro & Dimensão & Descrição & $\begin{array}{c}\text { Valor } \\
\text { especificado }\end{array}$ \\
\hline EPS & COM e HOU & Elasticidade dos gastos das famílias & 0,73 a 1,27 \\
EXP_ELAST & COM & Elasticidades da demanda por exportações & 0,38 a 8,33 \\
FRISCH & HOU & Parâmetro de Frisch & $-1,94$ \\
DPRC & IND & Taxa de depreciação & 0,0342 \\
QRATIO & IND & Razão investimento/capital (máxima/tendência) & 4 \\
RNORMAL & IND & Taxa de retorno bruta normal & $14,30 \%$ \\
GRETEXP & IND & Taxa de retorno bruta esperada & $14,30 \%$ \\
GROTREND & IND & Razão investimento/capital (tendência) & 0,064 \\
ALPHA & IND & Elasticidade do investimento & 4,8 \\
ELASTWAGE & IND & Elasticidade do salário em relação ao emprego & 0,66 \\
SIGMA1 & COM & Elasticidade Armington de subs- & 0,27 a 3,59 \\
SIGMA1OUT & IND & tituição: uso intermediário & 0,5 \\
SIGMA1PRIM & Elasticidades de transformação CET & 0,27 a 1,58 \\
SIGMA2 & EOM & Elasticidade de substituição CES & para fatores primários \\
SIGMA3 & COM & Elasticidade de Armington das famílias & 0,27 a 3,59 \\
\hline
\end{tabular}

Fonte: Elaboração própria.

O teste de sensibilidade estabeleceu um intervalo de 50\% para esses parâmetros, com distribuição uniforme. Dada a hipótese de distribuição, os resultados foram definidos em um intervalo de confiança rigoroso a 95\%, ou seja, de acordo com a desigualdade de Chebschev equivale a 4,47 desvios padrões em relação à média. Os testes mostram que os resultados agregados (PIB, investimento, consumo, etc.) e setoriais para muitas elasticidades são robustos, se mostrando menos sensíveis à variação das elasticidades supracitadas.

As Tabelas 8 e 9 apresentam os resultados para as elasticidades mais importantes para os objetivos da simulação e que provocaram os maiores desvios em relação à média. Os intervalos indicam que os resultados de algumas ocupações se mostraram levemente sensíveis à parametrização. Os resultados para a ocupação de Gerentes e Outros trabalhadores se mostraram sensíveis às elasticidades ELASTWAGE e SIGMAlPRIM. Os impactos sobre Diretores também apresentaram mudança de sinal para a elasticidade SIGMAIPRIM, para a simulação de restrição de engenheiros. Em contrapartida, nenhum resultado de ocupação foi sensível as demais elasticidades, mostrando robustez nos resultados. 
Tabela 10 - Análise de sensibilidade para elasticidades selecionadas da simulação de técnicos

\begin{tabular}{|c|c|c|c|c|c|c|c|c|c|}
\hline \multirow{3}{*}{ Variáveis } & \multicolumn{9}{|c|}{ Simulação Restrição de Técnicos } \\
\hline & \multicolumn{3}{|c|}{$\begin{array}{l}\text { Elasticidade do } \\
\text { salário em relação } \\
\text { ao emprego }\end{array}$} & \multicolumn{3}{|c|}{$\begin{array}{l}\text { Elasticidade de } \\
\text { substituição CES para } \\
\text { fatores primários }\end{array}$} & \multicolumn{3}{|c|}{$\begin{array}{l}\text { Elasticidade do } \\
\text { investimento }\end{array}$} \\
\hline & Média & $\begin{array}{l}\text { Interve } \\
\text { Confi }\end{array}$ & $\begin{array}{l}\text { alo de } \\
\text { iança }\end{array}$ & Média & $\begin{array}{l}\text { Interva } \\
\text { Confie }\end{array}$ & $\begin{array}{l}\text { alo de } \\
\text { iança }\end{array}$ & Média & $\begin{array}{l}\text { Inter } \\
\text { Con }\end{array}$ & $\begin{array}{l}\text { alo de } \\
\text { iança }\end{array}$ \\
\hline PIB & $-0,68$ & $-1,05$ & $-0,31$ & $-0,68$ & $-1,14$ & $-0,21$ & $-0,66$ & $-0,68$ & $-0,65$ \\
\hline Consumo das Famílias & $-1,69$ & $-1,82$ & $-1,57$ & $-1,71$ & $-2,53$ & $-0,88$ & $-1,68$ & $-1,73$ & $-1,64$ \\
\hline Investimento & $-1,47$ & $-2,24$ & $-0,71$ & $-1,47$ & $-2,80$ & $-0,40$ & $-1,43$ & $-1,52$ & $-1,35$ \\
\hline Exportações & 0,72 & 0,02 & 1,43 & 0,77 & $-0,13$ & 1,66 & 0,75 & 0,65 & 0,86 \\
\hline Emprego Total & $-0,68$ & $-1,31$ & $-0,06$ & $-0,66$ & $-0,93$ & $-0,40$ & $-0,66$ & $-0,69$ & $-0,64$ \\
\hline Emprego de Diretores & $-1,89$ & $-2,37$ & $-1,42$ & $-1,89$ & $-2,21$ & $-1,56$ & $-1,88$ & $-1,90$ & $-1,86$ \\
\hline Emprego de Gerentes & $-1,23$ & $-1,95$ & $-0,50$ & $-1,22$ & $-1,72$ & $-0,71$ & $-1,20$ & $-1,27$ & $-1,14$ \\
\hline Emprego de Técnicos & $-5,00$ & $-5,00$ & $-5,00$ & $-5,00$ & $-5,00$ & $-5,00$ & $-5,00$ & $-5,00$ & $-5,00$ \\
\hline Emprego de Engenheiros & $-6,62$ & $-6,86$ & $-6,39$ & $-6,60$ & $-7,66$ & $-5,55$ & $-6,63$ & $-6,80$ & $-6,45$ \\
\hline Emprego de Outros trabalhadores & $-0,34$ & $-1,05$ & 0,38 & $-0,32$ & $-0,70$ & 0,06 & $-0,32$ & $-0,39$ & $-0,24$ \\
\hline
\end{tabular}

Fonte: Elaboração própria.

Tabela 11 - Análise de sensibilidade para elasticidades selecionadas da simulação de engenheiros

\begin{tabular}{|c|c|c|c|c|c|c|c|c|c|}
\hline \multirow{3}{*}{ Variáveis } & \multicolumn{9}{|c|}{ Simulação Restrição de Engenheiros } \\
\hline & \multicolumn{3}{|c|}{$\begin{array}{l}\text { Elasticidade do } \\
\text { salário em relação } \\
\text { ao emprego }\end{array}$} & \multicolumn{3}{|c|}{$\begin{array}{l}\text { Elasticidade de } \\
\text { substituição CES para } \\
\text { fatores primários }\end{array}$} & \multicolumn{3}{|c|}{$\begin{array}{l}\text { Elasticidade do } \\
\text { investimento }\end{array}$} \\
\hline & Média & $\begin{array}{r}\text { Interva } \\
\text { Confic }\end{array}$ & $\begin{array}{l}\text { alo de } \\
\text { iança }\end{array}$ & Média & $\begin{array}{l}\text { Inter } \\
\text { Con }\end{array}$ & $\begin{array}{l}\text { alo de } \\
\text { iança }\end{array}$ & Média & & $\begin{array}{l}\text { alo de } \\
\text { íança }\end{array}$ \\
\hline PIB & $-0,27$ & $-0,39$ & $-0,16$ & $-0,28$ & $-0,54$ & $-0,01$ & $-0,27$ & $-0,37$ & $-0,16$ \\
\hline Consumo das Famílias & $-0,34$ & $-0,44$ & $-0,25$ & $-0,35$ & $-0,67$ & $-0,03$ & $-0,34$ & $-0,47$ & $-0,20$ \\
\hline Investimento & $-1,22$ & $-1,45$ & $-0,99$ & $-1,25$ & $-2,10$ & $-0,05$ & $-1,21$ & $-1,76$ & $-0,66$ \\
\hline Exportações & $-0,21$ & $-0,33$ & $-0,09$ & $-0,20$ & $-0,33$ & $-0,07$ & $-0,20$ & $-0,38$ & $-0,02$ \\
\hline Emprego Total & $-0,18$ & $-0,35$ & 0,00 & $-0,17$ & $-0,32$ & $-0,03$ & $-0,17$ & $-0,21$ & $-0,12$ \\
\hline Emprego de Diretores & $-0,19$ & $-0,37$ & $-0,01$ & $-0,19$ & $-0,42$ & 0,04 & $-0,18$ & $-0,19$ & $-0,16$ \\
\hline Emprego de Gerentes & $-0,12$ & $-0,33$ & 0,09 & $-0,12$ & $-0,44$ & 0,21 & $-0,10$ & $-0,12$ & $-0,09$ \\
\hline Emprego de Técnicos & $-1,22$ & $-1,37$ & $-1,08$ & $-1,22$ & $-1,40$ & $-1,04$ & $-1,21$ & $-1,22$ & $-1,20$ \\
\hline Emprego de Engenheiros & $-5,00$ & $-5,00$ & $-5,00$ & $-5,00$ & $-5,00$ & $-5,00$ & $-5,00$ & $-5,00$ & $-5,00$ \\
\hline Emprego de Outros trabalhadores & $-0,11$ & $-0,28$ & 0,06 & $-0,11$ & $-0,31$ & 0,08 & $-0,10$ & $-0,13$ & $-0,08$ \\
\hline
\end{tabular}

Fonte: Elaboração própria. 